\title{
Justicia, procedimiento y acción de revisión. El principio de culpabilidad frente a la cosa juzgada*
}

\author{
JUSTICE, PROCEDURE, AND REVISION ACTION. THE CULPABILITY PRINCIPLE FACING RES JUDICATA
}

JUAN PABLO MAÑALICH R**

\section{RESUMEN}

El trabajo presenta una reconstrucción racional de la regulación de la acción de revisión, plasmada en el Código Procesal Penal, que se sustenta en una caracterización del proceso penal como un contexto de justicia procedimental impura e imperfecta. Sobre esta base se explica cómo la regulación de la revisión es indicativa de un compromiso con un "principio de valoración asimétrica" del riesgo de una decisión sustantivamente injusta. Después de ofrecer una sistematización de las cinco causales de revisión legalmente previstas, el artículo se cierra con una doble desambiguación de la noción procesalmente relevante de inocencia.

\section{ABSTRACT}

The paper presents a rational reconstruction of the regulation of so called "revision action", established in the Chilean Penal Procedural Code, that rests upon a characterization of the criminal trial as a context of impure and imperfect procedural justice. Upon this basis, it is explained how that regulation is indicative of a commitment to a "principle of asymmetrical valuation" of the risk of a substantively unjust decision. After offering a systematization of the five legally acknowledged revision grounds, the paper closes with a double disambiguation of the procedurally relevant notion of innocence.

\section{PALABRAS CLAVE}

Acción de revisión, justicia procedimental imperfecta, valoración asimétrica de condenas y absoluciones injustas, concepto de inocencia.

\section{KEY WORDS}

Revision action, imperfect procedural justice, asymmetrical valuation of unjust convictions and acquittals, concept of innocence.

\footnotetext{
*Versiones preliminares de este trabajo fueron presentadas como ponencias en el seminario Juicio a los tribunales: aplicación, decisión y creación del derecho, celebrado en la Universidad Alberto Hurtado, la Universidad de Chile y la Universidad Diego Porta les los días 16 y 17 de agosto de 2018, así como en las VI Jornadas Chilotas de Derecho, celebradas en Castro los días 24 y 25 de agosto del mismo año; agradezco a las y los participantes de ambos foros por las observaciones, y muy especialmente a María Beatriz Arriagada por su acucioso comentario de la primera de las dos ponencias. Vayan mis agradecimientos, asimismo, para Flavia Carbonell, Mauricio Duce, Javier Contesse y Alejandra Olave, por sus valiosas sugerencias, y también a quienes oficiaron como árbitros anónimos en el proceso de revisión del trabajo, por algunas observaciones que hicieron posible corregir varios errores de fondo y forma.

** Doctor en derecho, Universidad de Bonn. Profesor titular y director del Departamento de Ciencias Penales, Facultad de Derecho, Universidad de Chile. Dirección postal: Av. Santa María 076, Providencia, Santiago, Chile. Dirección electrónica: jpmanalich@derecho.uchile.cl.
} 


\section{Introducción}

En su artículo titulado "La pretensión punitiva originaria en relación con aquella según el juzgamiento", observaba Binding que "la relación jurídico-penal entre el Estado y el condenado, establecida en el juzgamiento penal que alcanza fuerza de cosa juzgada, no es otra que la relación originaria entre ambos, adaptada para su realización", para entonces agregar: "Después de la emisión del juzgamiento es inconcebible la subsistencia de la última. Una garantía fuerte de la corrección de esta conclusión la ofrece la experiencia de que, una vez emitido el juzgamiento dotado de fuerza de cosa juzgada, la vida jurídica práctica no vuelva a preguntar por la relación jurídica originaria. Sólo el temor de que haya sido condenado un inocente puede suscitarla" ${ }^{1}$.

En la terminología de Binding, la pretensión punitiva originaria es aquella que el Estado tiene frente al responsable de un hecho punible al interior de la correspondiente "relación jurídico-penal originaria", que se funda en la existencia (imputable) de ese hecho punible; por su parte, la pretensión punitiva "según el juzgamiento" es aquella que el Estado tiene frente al condenado en cuanto afirmada a través de la sentencia condenatoria que declara, con fuerza de cosa juzgada, la existencia del respectivo hecho punible ${ }^{2}$. Con ello, la observación de Binding apunta a que la sentencia definitiva condenatoria que declara la existencia de la pretensión punitiva del Estado contra quien es condenado como responsable de algún hecho punible, especificándola $-y$ así "adaptándola" - para su materialización a través de la ejecución de la pena judicialmente impuesta, en cuanto adquiere fuerza de cosa juzgada clausura la posibilidad de una ulterior tematización procesal de la pregunta por la existencia o inexistencia de la pretensión punitiva originaria ${ }^{3}$, siendo el caso que únicamente la preocupación por la eventual inocencia de quien ha sido condenado justificaría reabrir esa posibilidad.

Esta observación ofrece una clave de la mayor importancia para emprender la reconstrucción racional de la regulación de la acción de revisión establecida en el Código Procesal Penal (en adelante, "CPP") que se desarrollará en el marco del presente trabajo. Pues la cita de Binding sugiere, por una parte, que es la preocupación por la eventualidad de que haya sido condenada una persona inocente lo que sustenta el desconocimiento retrospectivo de la fuerza de cosa juzgada ya adquirida por la sentencia condenatoria. Al mismo tiempo, y por otra parte, el pasaje vuelve inmediatamente inteligible que la injusticia predicable de la condena de un inocente consiste, como tal, en la falta de adecuación de esa condena para con la regulación penal sustantiva que fija los términos de la correspondiente "relación jurídico-penal originaria", al interior de la cual quien fuera condenado resultaba, empero, inocente de aquello que se le imputara ${ }^{4}$. Que la sentencia condenatoria ya firme pronunciada contra quien de hecho es inocente no logra hacer de este un "criminal", en el sentido de que no logra fundamentar una culpabilidad en efecto inexistente, es lo que expresa la tesis según la cual una cosa juzgada "positiva" es incompatible con la estructura del proceso penal ${ }^{5}$.

\footnotetext{
${ }^{1}$ BINDING (1915), p. 292.

${ }^{2}$ BINDING (1915), pp. 267 y ss. Al respecto, véase MAÑALICH (2010a), pp. 145 y ss.

${ }^{3}$ La clausura de esa posibilidad al interior del proceso en el cual la sentencia es pronunciada es el efecto propio de lo que tradicionalmente se tematiza como la su fuerza de cosa juzgada formal, en tanto que la clausura de esa posibilidad a través del desarrollo de un nuevo proceso, el efecto de su fuerza de cosa juzgada material. Así ya BENNECKE Y BELING (1900), pp. 405 y ss.

${ }^{4}$ Esto llevaba a que Binding agudamente observara que, en tal caso, la sentencia condenatoria no tiene carácter declarativo, sino (problemáticamente) constitutivo; véase BINDING (1915), pp. 286, 289 y ss.

${ }^{5}$ Así ya BENNECKE Y BELING (1900), p. 409. Sobre el problema, véase GRECO (2015), pp. 328 y ss., 332 y ss.
} 


\section{La acción de revisión bajo el diseño del proceso penal como contexto de justicia procedimental imperfecta}

\subsection{La revisión como acción de nulidad}

La acción de revisión, regulada en el párr. 3ำ del Título VIII del Libro IV del CPP, admite ser preliminarmente caracterizada como un mecanismo procesal de desconocimiento de la fuerza de cosa juzgada de sentencias condenatorias cuya injusticia, entendida como una falta de satisfacción de condiciones de adecuación jurídica de la respectiva decisión condenatoria, logra ser sobrevinientemente detectada. Esta caracterización necesita ser debidamente fundamentada.

Que el mecanismo de la revisión exhibe la naturaleza jurídica de una acción procesal (declarativa), y no de un recurso ${ }^{6}$, se sigue de que su efecto precisamente consista en el desconocimiento de la fuerza de cosa juzgada material de una sentencia condenatoria que como tal ya debe haber adquirido fuerza de cosa juzgada formal, en cuanto ha de tratarse de una sentencia firme (y en tal medida, inimpugnable), según reza el inc. 10 del art. 473 del CPP ${ }^{7}$. Esto contrasta con que la procedencia de un mecanismo de impugnación consistente en un recurso dependa de que la resolución en cuestión aún no se encuentre firme, y así no haya todavía adquirido fuerza de cosa juzgada. Ello se ve complementado por la circunstancia de que la misma disposición caracterice el mecanismo de la revisión como uno que opera extraordinariamente, haciendo posible la anulación, por parte de la Corte Suprema, de una sentencia condenatoria respecto de la cual se configure alguna de las causales instituidas en los literales establecidos bajo el ya referido inc. 1‥ De ahí que, como agudamente sugiriera Binding, la admisibilidad del mecanismo de la revisión tenga como consecuencia que toda sentencia penalmente condenatoria pase a contener, implícitamente, una cláusula rebus sic stantibus ${ }^{8}$. Finalmente, que la regulación de la revisión se encuentre dispuesta en un párrafo cuyo epígrafe reza "Ejecución de las sentencias condenatorias y medidas de seguridad", refuerza la conclusión ya alcanzada. Pues ello hace explícito que el mecanismo así configurado se encuentra referido a sentencias condenatorias que han llegado a ser ejecutables, sea que se trate de una sentencia todavía no ejecutada, sea que se trate de una sentencia en actual ejecución, sea que se trate de una sentencia ya (íntegramente) ejecutada, procediendo la revisión en este último caso para que el condenado o - en caso de haber muerto este- sus herederos puedan "rehabilitar su memoria", según lo prevé el art. 474 del CPP.

El énfasis en la naturaleza jurídica del mecanismo de la revisión como acción procesal tiene importancia para dar cuenta de un rasgo compartido por las cinco causales, por lo demás sumamente heterogéneas, que bajo el art. 473 la hacen procedente. Se trata, en efecto, de causales constituidas por situaciones cuya específica gravedad, desde el punto de vista de la injusticia de la

\footnotetext{
${ }^{6}$ Acertadamente al respecto, FERNÁNDEZ Y OLAVARRÍA (2018), pp. 1196 y ss. Véase también MOSQUERA Y MATURANA (2012), pp. 579 y ss., quienes a pesar de ello hacen uso de la expresión "recurso" en múltiples contextos de su exposición; en el mismo sentido, ya HORVITZ Y LÓPEZ (2004), pp. 447 y ss., quienes para así honrar lo que identifican como la "tradición procesal chilena" mantienen el estudio de la acción de revisión bajo el capítulo sistemáticamente dedicado a los recursos. En referencia inmediata a la regulación de la revisión bajo la Ley de Enjuiciamiento Criminal española, también OLIVER (2007), pp. 401 y ss., hace uso de la expresión "recurso" para caracterizar el mecanismo en cuestión, en congruencia con el nomen iuris allí legalmente impuesto, a pesar de que doctrinalmente esta denominación es tenida por técnicamente errada; véase solo VERNENGO (2015), pp. 46 y ss., con múltiples referencias ulteriores.

${ }^{7}$ Acerca de la redefinición de la noción de firmeza de una resolución judicial en el sentido de su carácter inimpugnable, identificando esta última cualidad con la noción del así llamado "efecto de cosa juzgada formal”, véase FERRER (2005), pp. 58 y ss. Para la caracterización de la cosa juzgada formal como presupuesto de la cosa juzgada material, BENNECKE Y BELING (1900), pp. 407 y ss.

8 BINDING (1915), p. 338, quien no restringía la observación al ámbito de las sentencias penalmente condenatorias, en razón de la admisión, bajo el derecho alemán entonces vigente, de una revisión en perjuicio del acusado; al respecto, véase ya BENNECKE Y BELING (1900), pp. 599 y ss., 601 y ss. Sobre la particularidad del derecho chileno a este último respecto, véase más abajo, 3.1.
} 
condena pronunciada, vuelve jurídicamente insoportable que la sentencia llegue a ser ejecutada o siga siendo ejecutada, según cuál sea la oportunidad en que la injusticia de la condena respectiva llegue a ser sobrevinientemente detectada 9 .

\subsection{El proceso penal como contexto de justicia procedimental imperfecta}

Para identificar con mayor precisión en qué puede consistir la injusticia asociada a cada una de las cinco causales, cabe considerar bajo qué condiciones y desde qué perspectiva puede responderse la pregunta por la justicia del resultado de un proceso penal (de cognición) que en efecto resulta en el pronunciamiento de una sentencia de término. A este respecto, tiene sentido asumir que el diseño regulativo de un determinado modelo de proceso penal sometido al principio de culpabilidad hace de cada proceso particular ajustado al procedimiento así diseñado un caso de lo que John Rawls denominara "justicia procedimental imperfecta"10.

Esta categoría se corresponde con una de las dos variantes de lo que, sin distorsionar el punto de vista asumido por Rawls, cabe llamar "justicia procedimental impura". Definitorio de esta última categoría genérica es el hecho de que la justicia del resultado del proceso respectivo dependa de la satisfacción de un criterio sustantivo (de justicia), que es conceptualmente independiente de la estructura del procedimiento en cuestión. En tal medida, la relación que aquí se da entre la adecuación del concreto proceso al conjunto de exigencias definitorias del procedimiento, por un lado, y la justicia del resultado del proceso, por otro, sería instrumental, y así de naturaleza extrínseca. La inexistencia de semejante criterio sustantivo es lo distintivo, como contrapartida, de lo que Rawls denomina formas de "justicia procedimental pura". La relación que aquí se da entre la adecuación del proceso concreto al procedimiento y la justicia del resultado de aquel es constitutiva, y así de naturaleza intrínseca ${ }^{11}$. Y a su vez, la distinción, practicada al interior de la categoría de justicia procedimental impura, entre formas de justicia procedimental perfecta y formas de justicia procedimental imperfecta se construye sobre la pregunta de si el diseño del procedimiento asegura o no, respectivamente, la justicia (extrínseca) del resultado con arreglo al correspondiente criterio sustantivo.

Según ya se anticipara, Rawls mismo observaba que una forma paradigmática de justicia procedimental imperfecta se corresponde con el diseño de cualquier modelo de proceso penal sometido al principio de culpabilidad ${ }^{12}$. Se trata, en primer lugar, de una forma de justicia procedimental impura, porque el principio de culpabilidad provee a lo menos un criterio sustantivo de cuya satisfacción depende que el resultado del respectivo proceso penal sea justo, a saber: "el imputado ha de ser declarado culpable si y solo si ha cometido el delito que se le imputa"13. Y se

\footnotetext{
${ }^{9}$ Esto no significa que la caracterización de esas cinco causales pueda reducirse a la observación de que ellas "constituyen casos extremos en que resulta evidente que la legitimidad de la sentencia que impone la sanción penal se encuentra en crisis por una circunstancia conocida posteriormente que evidencia que ésta se fundamenta en un indudable error de hecho o ha tenido un origen fraudulento", como se lee en HORVITZ Y LÓPEZ (2004), p. 451.

${ }^{10}$ RAWLS (1999), pp. 73 y ss. Al respecto, véase HÖRNLE (2004), pp. 176 y ss.; MAÑALICH (2010a), pp. 147 y ss.; también MAÑALICH (2014a), pp. 399 y ss. En detalle sobre el problema, GRECO (2015), pp. 239 y ss., 243 y ss. Advirtiendo la importancia de esta caracterización para la reconstrucción dogmática de la regulación de la revisión, véase ya FERNÁNDEZ Y OLAVARRÍA (2009), pp. 234 y ss.; también FERNÁNDEZ Y OLAVARRÍA (2018), p. 1212.

${ }^{11}$ Al respecto, NEUMANN (1989), pp. 54 y ss.; también CELANO (2001), pp. 409 y ss. Sobre la distinción entre valor intrínseco y el valor instrumental atribuible a algún diseño procedimental, véase ya BAYÓN (2000), pp. 85 y ss.

12 Véase al respecto DUFF (1986), pp. 110 y ss. Como debería ser obvio, tal caracterización no es privativa de los modelos de proceso penal; véase ya FERRER (2012a), p. 264.

${ }^{13}$ RAWLS (1999), p. 73. Nótese que, en contra de lo sostenido por ATRIA (2016), pp. 382 y ss., nota 4, ello no se ve afectado por el hecho
} 
trata, en segundo lugar, de una forma de justicia procedimental imperfecta, porque "parece imposible diseñar las reglas jurídicas de modo tal que ellas siempre lleven al resultado correcto" ${ }^{14}$. En la medida en que la insatisfacción del criterio sustantivo de justicia determina la incorrección del resultado del proceso, la injusticia así configurada admite ser tematizada como constitutiva de un error, en el sentido de una discrepancia entre la declaración judicial de la satisfacción de los presupuestos fácticos y jurídicos de una condena y la efectiva falta de satisfacción de alguno o algunos de esos presupuestos, sin que ese error necesite descansar en algún déficit de corrección procedimental del proceso en cuestión ${ }^{15}$.

La exhaustividad del esquema clasificatorio sugerido por Rawls ha sido recientemente puesta en duda por Atria, según quien Rawls habría omitido tematizar la categoría que resultaría de combinar la inexistencia de un estándar de justicia extrínseco y la imposibilidad de diseñar un "procedimiento infalible", categoría que Atria propone identificar a través de la noción de una "justicia puramente procesal imperfecta" ${ }^{16}$. Atria advierte que, a primera vista, la postulación de tal categoría parece no tener sentido alguno, pues la pregunta por la infalibilidad del procedimiento solo resulta pertinente si se dispone de algún parámetro, independiente del diseño de ese procedimiento, cuya satisfacción hubiera de ser asegurada o promovida por este. Con todo, Atria sugiere que esa categoría aparentemente desprovista de sentido identificaría "el tipo fundamental para entender las instituciones"17.

El argumento ofrecido para sustentar esta última afirmación sugiere, empero, que la pretendida categoría es reducible a un género de situaciones en las cuales el correspondiente estándar de justicia, extrínseco al procedimiento, se encuentra especificado como un criterio unilateralmente negativo de justicia, esto es, en la forma de un criterio de mera injusticia sustantiva, cuya particularidad consiste en que la inversión de tal criterio no resulta en la formulación de un criterio positivo de justicia sustantiva. Precisamente tratándose de las situaciones que sirven de contexto a la observación de Atria, que involucran relaciones de intercambio contractual, es fácil advertir, por ejemplo, que las reglas sobre la así llamada "lesión enorme" desempeñan una función de esa índole: se trata de reglas que fijan criterios de reconocimiento de (crasa) injusticia conmutativa del intercambio en cuestión, sin que a través de la inversión de esas reglas se obtengan criterios positivos de justicia conmutativa para el mismo intercambio ${ }^{18}$.

La observación precedente es importante para lo que aquí interesa, en cuanto lleva a la constatación de que el criterio sustantivo de cuya satisfacción depende la justicia o injusticia del resultado de un proceso penal tiene el carácter de un criterio no solo bivalente, sino asimismo

de que la corrección, la legitimidad o la aceptabilidad del resultado de un proceso penal pueda depender, como lo advirtiera Rawls, de la realización de "otros fines del derecho". Pues eso solo significaría que el correspondiente criterio de justicia no es el único estándar con relevancia para evaluar normativamente el resultado alcanzado. Precisamente desde este punto de vista adquiere relevancia el discurso de la teoría de la justificación de la pena, tradicionalmente determinado por la rivalidad entre concepciones retribucionistas y concepciones prevencionistas, para el diseño del correspondiente modelo de proceso penal. Para el (mero) esbozo de un modelo de la primera clase, véase MAÑALICH (2010a), pp. 45 y ss., con referencias ulteriores.

${ }^{14}$ RAWLS (1999), p. 75.

${ }^{15}$ Fundamental BINDING (1915), pp. 277 y ss., 281 y ss.; véase también NEUMANN (1989), pp. 52 y ss., quien acertadamente identifica la justicia del resultado del proceso con "la realización del derecho penal material". Para un punto de vista enteramente coincidente, véase LAUDAN (2006), pp. 9 y ss.: "[...] errors, in my sense, have nothing to do with whether the system followed the rules [...] and everything to do with whether judicial outcomes convict the guilty and free the innocent".

${ }^{16}$ ATRIA (2016), pp. 381 y ss., con nota 3.

${ }^{17}$ ATRIA (2016), p. 382.

${ }^{18}$ Con ello, la constatación de que el criterio unilateralmente negativo de justicia sustantiva se ve cumplido fundamenta la ase rción de que el resultado alcanzado no es justo (cuya forma enunciativa sería la de una negación interna: "es verdad que no-p"), sin que ella pueda ser confundida con la aserción de que al resultado no se aplica un criterio de justicia sustantiva (cuya forma enunciativa sería la de una negación externa: "no es verdad que $p$ "). 
bilateral. Su bivalencia se expresa en que el principio de culpabilidad determina la justicia de cualquiera de los dos resultados que, de manera conjuntamente exhaustiva y mutuamente excluyente, son susceptibles de ser alcanzados a través de la sentencia definitiva que pone término al proceso respectivo. Su bilateralidad, por su parte, se expresa en que el principio de culpabilidad determina tanto la justicia de una decisión (de condena o absolución) que satisface ese criterio sustantivo, como la injusticia de una decisión (de condena o absolución) que no lo satisface. La conjunción de la bivalencia y la bilateralidad del criterio se expresa en que valgan los siguientes dos pares de proposiciones: la condena de quien es culpable del hecho punible que se le imputa es sustantivamente justa, así como lo es la absolución (y por implicación: la no-condena) de quien es inocente del hecho imputado; y la condena de quien es inocente del hecho punible que se le imputa es sustantivamente injusta, así como lo es la absolución (y por implicación: la no-condena) de quien es culpable del hecho imputado.

Como habrá de examinarse más abajo, sin embargo, es definitorio de los modelos de proceso penal que pretenden satisfacer los parámetros de legitimación asociados a la forma ideal de un Estado de derecho que el riesgo de un resultado procesal sustantivamente injusto quede sometido a un principio de valoración asimétrica, el cual, bajo el derecho chileno, impacta directamente en el diseño del mecanismo de la revisión ${ }^{19}$.

\subsection{La gradualidad de la distinción entre la perfección y la imperfección de las formas de justicia procedimental impura}

Pero antes de llegar a ello es necesario ilustrar más detalladamente el esquema clasificatorio que sirve de contexto a la caracterización de los modelos más usuales de proceso penal como formas de justicia procedimental imperfecta. Para ello puede ser útil considerar, como contraste, el ejemplo de una pretendida forma de justicia procedimental perfecta que Rawls mismo ofrece:

A number of men are to divide a cake: assuming that the fair division is an equal one, which procedure, if any, will give this outcome? Technicalities aside, the obvious solution is to have one man divide the cake and get the last piece, the others being allowed their pick before him. He will divide the cake equally, since in this way he assures for himself the largest share possible. [...] Of course, certain assumptions are made here, such as that the man selected can divide the cake equally, wants as large a piece as he can get, and so on. But we can ignore these details ${ }^{20}$.

Aquí es fundamental reparar en que Rawls está sugiriendo que el seguimiento de la regla susceptible de ser formulada a través del enunciado "quien parte se lleva la última parte" (y a la que en lo que sigue me referiré como la regla "R") alcanzaría a asegurar la satisfacción del estándar de justicia distributiva, referido a la partición de la torta en cuestión, según el cual cada uno de los presentes debe recibir una porción de torta igual a la que recibe cada uno de los demás ( $y$ al cual me referiré como el estándar " $\left.\mathrm{E}^{\prime}\right)^{21}$. Aun no problematizando el presupuesto psicológico sobre el cual parecería descansar la eficacia instrumental de R para el aseguramiento de la obtención de un resultado justo con arreglo a $\mathrm{E}$, consistente en que quien deba efectuar la partición de la torta (a

\footnotetext{
19 Véase más abajo, 3.2 .

${ }^{20}$ RAWLS (1999), p. 74.

${ }^{21}$ Para un análisis de la estructura genérica de un juicio de corrección, entendido como un juicio que establece la existencia de una relación de ajuste entre el respectivo objeto del juicio y el parámetro o estándar bajo el cual el objeto es juzgado, véase CARBONELL (2017), pp. 5 y ss.
} 
quien me referiré como el partidor "P") mostraría una disposición favorable a la promoción del propio interés que haría suficientemente probable un despliegue del máximo esfuerzo de su parte por alcanzar una partición igualitaria ${ }^{22}$, cabe observar que la satisfacción del presupuesto operacional consistente en que $\mathrm{P}$ sea capaz de efectuar una partición igualitaria tampoco logra excluir la posibilidad de que la partición efectuada por $P$ resulte injusta bajo $E$. Pues que $P$ tenga esa capacidad consiste en que $\mathrm{P}$ exhiba una determinada propiedad disposicional, cuya atribución a $\mathrm{P}$, empero, es compatible con que, en una ocasión particular cualquiera, P no logre realizar una partición igualitaria de la torta ${ }^{23}$.

Con ello, y pace Rawls, el sometimiento de la partición de la torta a R no logra asegurar que el resultado de la partición satisfaga E. Esto sugiere que, en contra de lo sostenido por Rawls, la distinción pretendidamente binaria entre formas de justicia procedimental perfecta y formas de justicia procedimental imperfecta debería ser redefinida, más bien, como una diferenciación gradual al interior de la categoría de la justicia procedimental impura, según cuán probable sea la obtención de un resultado sustantivamente justo, bajo el estándar aplicable, a través del seguimiento de las reglas definitorias del procedimiento en cuestión. Con ello, mientras los conceptos de justicia procedimental pura e impura se comportan como conceptos propiamente clasificatorios, los conceptos de justicia procedimental perfecta e imperfecta adquieren, más bien, el carácter de conceptos ordenadores ${ }^{24}$. Una ventaja de esta redefinición consiste en que ella hace más fácil advertir por qué, en general, el diseño del respectivo procedimiento podría incorporar mecanismos de justicia puramente procedimental para compensar, aun cuando "imperfectamente", la falta de satisfacción del correspondiente estándar sustantivo de justicia ${ }^{25}$.

Volviendo al ejemplo propuesto por Rawls, ello es exactamente lo que ocurriría si, advirtiendo que nadie puede estar suficientemente seguro de que, de ser designado para ello, logrará realizar una partición igualitaria de la torta, los involucrados acordasen establecer una regla de sorteo para

\footnotetext{
${ }^{22}$ Como es sabido, una moderada disposición a la promoción del auto-interés es explícitamente tematizada por Rawls como uno de los rasgos que exhibirían los participantes ("las partes") en la deliberación desarrollada en la así llamada "posición original” en pos de la formulación de los principios de justicia (puramente procedimental) que definirían los arreglos constitutivos de la estructura básica de la sociedad política respectiva; véase RAWLS (1999), pp. 15 y ss., 102 y ss.

${ }^{23}$ Pues mutatis mutandis: el hecho de que $X$ sea capaz de sumar - en el sentido de que $X$ sabe cómo sumar - no se ve desafiado por el hecho de que, en una ocasión particular, $\mathrm{X}$ yerre al efectuar una suma. Para un muy refinado análisis de las conexiones existentes entre las nociones de "saber-cómo" y "ser-capaz-de", véase HACKER (2013), pp. 154 y ss., 186 y ss.

${ }^{24}$ Fundamental para esta distinción, en clave jurídico-filosófica, ya RADBRUCH (1967), pp. 167 y ss., observando que los conceptos ordenadores se distinguen por expresar "propiedades graduables"; al respecto, véase también KINDHÄUSER (1984), pp. 469 y ss.

${ }^{25}$ Esto supone impugnar la afirmación de Celano, según la cual, desde el punto de vista jurídico, la distinción entre justicia procedimental imperfecta y justicia procedimental pura en último término colapsaría; véase CELANO (2001), pp. 411 y ss., 418 y ss., quien centra su argumento en el problema representado por las así llamadas "normas irregulares", cuyo análisis lo lleva, en la senda de Kelsen, a concluir que, "[d]esde el punto de vista de una teoría nomodinámica del Derecho, pues, la situación está definida por los dos rasgos siguientes: no disponibilidad de un criterio independiente de corrección, y garantía de éxito del procedimiento de juicio" (p. 424). Aquí basta con observar, por un lado, que Celano parece pasar por alto que la tematización de "si hay un órgano competente para determinar, en ejecución de un procedimiento determinado", la satisfacción de las "condiciones necesarias para la producción de una consecuencia jurídica cualquiera" (p. 421), vuelve pertinente la pregunta de si el órgano en cuestión es en efecto competente y de si la determinación que llegue a adoptar acerca de la satisfacción de tales condiciones en efecto tiene lugar en ejecución del procedimiento previsto. Esto sugiere que la posibilidad de que llegue a ser producida una decisión que no logre ser jurídicamente impugnada -que es lo que Kelsen tomaba como premisa en la formulación de su argumento acerca de la "cláusula alternativa tácita" - no logra suprimir la pregunta acerca de la validez (jurídica) de esa decisión. Por otro lado, Celano yerra al asumir que la distinción entre la validez y la aplicabilidad de una norma - que contribuye a disolver el problema precedentemente planteado- habría de ser entendida en la forma de una distinción gradual (o cuantitativa) al interior de un continuo que se identificaría con el género de la "juridicidad" de una norma cualquiera (pp. 419 y ss.). Pues ello desconoce que el hecho de que una norma llegue a ser aplicada, de manera jurídicamente eficaz, no depende en lo absoluto de que esa norma pertenezca a algún sistema jurídico ("estático") que integre la secuencia dinámica que se identifica con el orden jurídico de referencia; al respecto, véase NAVARRO Y RODRÍGUEZ (2014), pp. 132 y ss., 196 y ss. Para el esbozo de un argumento equivalente al aquí esgrimido, dirigido en contra de la "teoría jurídico-material de la cosa juzgada", véase NEUMANN (1989), pp. 63 y ss.
} 
la designación del partidor. Si bajo la vigencia de esta regla adicional $\mathrm{P}$ en efecto no lograse partir la torta de manera igualitaria, y ello llevase a que -en congruencia con el ya explicitado presupuesto psicológico- $P$ recibiera una porción más pequeña que la que recibirían los demás, la caracterización de este resultado como justo no podría estar fundada en la satisfacción de $E$, sino más bien en que la falta de satisfacción de E se vería compensada por la satisfacción de un estándar de justicia procedimental pura.

\subsection{Estándares de justicia sustantiva versus estándares de justicia procedimental}

Para lo que aquí interesa, es absolutamente fundamental no perder de vista que, en el caso recién considerado, el resultado alcanzado no deja de ser sustantivamente injusto. Esto importa, en razón de que el régimen de la acción de revisión plasmado en el CPP muestra, por una parte, que la injusticia sustantiva exhibida por una sentencia condenatoria no resulta compensable por la satisfacción de cualesquiera estándares de corrección procedimental ${ }^{26}$. En tal medida, tales estándares no logran exhibir el carácter de estándares de justicia procedimental pura. Al mismo tiempo, y por otra parte, la regulación de la revisión hace reconocible que existen vulneraciones especialmente graves de estándares de corrección procedimental susceptible de ser exhibida por una sentencia condenatoria cuya detección sobreviniente puede justificar una anulación de esta, sin que su justicia sustantiva necesite llegar a ser puesta en cuestión.

Esto último no quiere decir que una vulneración semejante de un estándar de corrección procedimental no muestre conexión alguna con la preocupación por una eventual injusticia del resultado del proceso bajo el correspondiente estándar sustantivo de justicia. Antes bien, los estándares de corrección procedimental cuya vulneración hace procedente la revisión de una sentencia condenatoria se dejan identificar precisamente por el hecho de que ellos fungen como indicadores de un riesgo suficientemente serio de que la decisión de condena sea sustantivamente injusta, sin que esto necesite ser in concreto comprobado ${ }^{27}$. Esta conexión teleológica entre la constatación de determinadas formas de incorrección procedimental y la sospecha estandarizada acerca de una posible injusticia sustantiva de la decisión de condena así alcanzada se explica por la circunstancia de que las reglas que configuran el procedimiento se orientan, decisiva aun cuando no exclusivamente, a minimizar las chances de que el estándar sustantivo de justicia en efecto resulte insatisfecho en la forma de la condena de quien es inocente.

Tal institucionalización de la preocupación por el aseguramiento de la justicia sustantiva del resultado del proceso explica, a su vez, que la eventual comprobación judicial de la satisfacción del principio de culpabilidad en cuanto criterio sustantivo de justicia no pueda tener lugar, procesalmente, sino bajo el presupuesto de que el proceso resultante en esa pretendida comprobación se ha ajustado a las reglas que configuran el procedimiento ${ }^{28}$. En contra de lo

\footnotetext{
${ }^{26}$ Fundamental al respecto, HÖRNLE (2004), pp. 185 y ss., 191 y ss., con especial énfasis en los así llamados mecanismos de "justicia consensual". Para una reciente y muy fundada puesta en cuestión de la legitimidad de los mecanismos de "justicia penal negociada" desde el punto de vista de su incidencia en la eventualidad de la condena de un acusado inocente, véase LASCURAín Y GASCÓN (2018), pp. 5 y ss., 12 y ss., en referencia inmediata a la Ley de Enjuiciamiento Criminal española.

${ }^{27}$ Véase BINDING (1915), pp. 293 y ss.

${ }^{28}$ Al respecto, ya BINDING (1915), pp. 277 y ss.; véase también NEUMANN (1989), pp. 67 y ss., quien analizando la plausibilidad del "modelo del juego" como alternativa teórica al "modelo del proceso como instrumento al servicio de la justicia", favorable a la disolución de "la conexión teleológica entre finalidad del procedimiento y reglas procedimentales", observaba que la satisfacción de las correspondientes exigencias de justicia procedimental solo podría ser entendida como una condición necesaria, pero no suficiente, de la justicia del resultado de un proceso penal. Acerca de la correspondiente noción de "corrección procesal", véase CARBONELL (2017), pp. 8 yss.
} 
sugerido por Atria, ello no admite ser reformulado en el sentido de que el proceso penal no contaría como un contexto de justicia procedimental imperfecta, "porque no hay un criterio independiente de los procedimientos que nos permitan [sic] calificar en este sentido una sentencia como «justa» o «injusta»"29. Pues aquí se confunde la constatación (acertada) de que la satisfacción de las reglas que configuran el procedimiento es constitutiva de la ocasión procesalmente legítima para declarar la satisfacción del principio de culpabilidad en cuanto criterio sustantivo de justicia de una decisión de condena o absolución ${ }^{30}$, con la sugerencia (infundada) de que la satisfacción de esas mismas reglas sería sin más constitutiva de la justicia de la decisión de condena o absolución.

Como se mostrará más abajo, la consideración precedente ofrece una clave de la mayor relevancia para diferenciar aquellas causales de revisión que son indicativas de una preocupación inmediatamente referida a la falta de satisfacción del principio de culpabilidad en cuanto criterio sustantivo de justicia del resultado del proceso, por un lado, de aquellas causales que son indicativas, más bien, de una preocupación inmediatamente referida a la vulneración de estándares procedimentales cuya observancia debería incrementar la probabilidad de que se vea satisfecho el criterio sustantivo de justicia, con independencia de que esto último tenga o no lugar, por otro. Antes de entrar en ello, sin embargo, es necesario incorporar una variable adicional en el análisis, concerniente a la manera en que la regulación procesal penal vigente institucionaliza asimétricamente la ya referida preocupación por la eventual insatisfacción del correspondiente criterio sustantivo de justicia.

\section{El principio de valoración asimétrica del riesgo de injusticia del resultado del proceso penal}

\subsection{La valoración asimétrica del riesgo de injusticia sustantiva del resultado del proceso}

Antes de proceder al análisis de la especificidad de las cinco causales de revisión enunciadas en el ya referido art. 473 , es crucial detenerse, según ya se anticipara, en un dato impuesto por la regulación plasmada en el CPP, que a su vez reproduce un rasgo igualmente definitorio del mecanismo de la revisión que contemplara el Código de Procedimiento Penal (en adelante, "CdPP") ${ }^{31}$. El dato regulativo en cuestión consiste en el hecho de que el mecanismo procesal de la revisión de sentencias penales se encuentre reservado para la posible anulación de sentencias condenatorias. Y esto se traduce, como contrapartida, en que una sentencia absolutoria en cuyo pronunciamiento pudiera culminar un proceso penal cualquiera no es susceptible de anulación por vía de revisión.

\footnotetext{
${ }^{29}$ ATRIA (2016), pp. 382 y ss., nota 4.

${ }^{30}$ Acerca del principio de "exclusividad procesal" de la aplicación de la legislación penal, entendido como un corolario de la garantía de “juicio previo" establecida en el inc. 1ㅇ del art. 10 del CPP, véase DEL Río (2009), pp. 67 y ss.

${ }^{31}$ Que, en lo fundamental, la regulación de la acción de revisión establecida en el CdPP haya sido traspasada in toto al CPP -en cuyo art. 473 fuera añadida, con todo, una quinta causal, establecida en su letra e), no contemplada en el CdPP - sugiere que en la institucionalización de un nuevo modelo de proceso penal se asumió como no problemática, sin más, la hipótesis de la compatibilidad de esa regulación de la revisión con los lineamientos básicos del nuevo modelo. La tendencia de la praxis a concentrar el ejercicio de la acción de revisión exclusivamente en la causal de la letra d) del art. 473 del CPP, así como las elevadísimas tasas de rechazo que marcan el comportamiento de la Corte Suprema como tribunal de revisión, documentadas en FERNÁNDEZ Y OLAVARRÍA (2009), pp. 216 y ss., 247 y ss., DUCE (2015), pp. 165 y ss., y DUCE (2018), pp. 11 y ss. y FERNÁNDEZ Y OLAVARRÍA (2018), pp. 1216 y ss., son indiciarias de lo problemática que resultó ser aquella hipótesis.
} 
Esta institucionalización asimétrica del mecanismo de la revisión, que está lejos de constituir una trivialidad desde el punto de vista del derecho comparado ${ }^{32}$, se deja explicar cómo la consecuencia de que la regulación de la revisión hace reconocible la adopción legislativa de un principio de valoración asimétrica del riesgo de injusticia del resultado del proceso penal ${ }^{33}$. Se trata aquí de un principio que informa el diseño del correspondiente modelo de proceso penal, en el sentido en que la expresión "principio" designa un estándar de corrección jurídica obtenido por vía de abducción a partir de estándares de menor abstracción, en los cuales dicho principio resulta "apoyado" 34 . Planteando el punto según los anglicismos que hace suya la doctrina procesal contemporánea, el principio de la valoración asimétrica del riesgo de injusticia del resultado del proceso se expresa en que el diseño procesal penal valora como más grave el riesgo de un "falso positivo", esto es, el riesgo de que sea tenida por verdadera una hipótesis fáctica en efecto falsa, cuya validación judicial lleve a que sea condenada una persona que no es culpable del hecho punible que se le imputara, que el riesgo de un "falso negativo", esto es, el riesgo de que no sea tenida por verdadera una hipótesis fáctica en efecto verdadera, cuya falta de validación judicial lleve a que sea absuelta una persona que es culpable del hecho punible que se le imputara ${ }^{35}$.

No es en absoluto autoevidente qué pudiera sustentar la institucionalización de semejante sesgo. Sin que aquí sea posible acometer la respuesta a esta pregunta con el debido detenimiento, se impone constatar que la usual apelación a la seriedad de los "bienes en juego" para el acusado resulta enteramente insuficiente como pretendido fundamento del sesgo en cuestión. Pues incurre en un mero apriorismo quien -encandilado por la hoy ya mítica caracterización de la intervención penal como una ultima ratio- asume que el menoscabo de uno o más bienes jurídicos del condenado resultante de la irrogación del mal en la que consiste la ejecución de una determinada sanción penal necesariamente habría de ser, siempre y en todo caso, más grave que el menoscabo susceptible de ser irrogado a través de la materialización de una consecuencia jurídica no revestida

\footnotetext{
32 Véase, por ejemplo, la regulación de la "revisión" (Wiederaufnahme) de un proceso concluido mediante un enjuiciamiento revestido de fuerza de cosa juzgada establecida en los $\S \S 359$ de la Ordenanza Procesal Penal alemana ("StPO"), que explícitamente prevé, en su $\S$ 362 , la posibilidad de una "revisión desfavorable al acusado", pudiendo la sentencia así revisada ser de naturaleza absolutoria; latamente al respecto, GRECO (2015), pp. 956 ss. En contraste con ello, si bien a contar de la modificación del art. 954 de la Ley de Enjuiciamiento Criminal española, dispuesta por la Ley 41/2015, de 5 de octubre, parecería que algunos de los motivos de revisión allí previstos pudieran ser insensibles a la variable del carácter condenatorio o absolutorio de la sentencia revisada, las reglas de los arts. 955 y 956, que definen quiénes tienen legitimación activa para su promoción e interposición, vuelven claro que la revisión solo procede pro reo; en referencia a la situación jurídica anterior a la ya referida modificación legal, véase VERNENGO (2015), pp. 71 y ss., 84 y ss.

${ }^{33}$ Véase asimismo FERRER (2007), pp. 139 y ss., 144 y ss.; fundamental al respecto LAUDAN (2006), pp. 29 y ss. En referencia al derecho chileno, ACCATINO (2011), pp. 484 y ss.; también VALENZUELA (2017), pp. 19 y ss., 96 y ss. Para una aproximación empírica al problema, véase CASTILLO (2013), pp. 256 y ss.

${ }^{34}$ Sobre este método de identificación abductiva de principios implícitos, asociada a una forma de coherentismo iuspositivista, véase ALONSO (2018), pp. 70 y ss., 77 y ss.

${ }^{35}$ Véase FERRER (2007), pp. 143 y 148; fundamental al respecto LAUDAN (2006), pp. 10 y ss., distinguiendo entre errores consistentes en la condena de quien es efectivamente inocente y errores consistentes en la falta de condena de quien es efectivamente culpable. La formulación aquí ofrecida es preferible a la sugerida por ACCATINO (2011), p. 487, quien identifica el riesgo de un falso positivo con "el riesgo de que se declare probada una proposición falsa", en tanto que el riesgo de un falso negativo, con "el riesgo de que se declare no probada una proposición verdadera". Esto no resulta suficientemente preciso, en cuanto no especifica la conexión entre la pro posición de cuya declaración como probada o no probada se trata y la decisión autoritativa fundamentada en la correspondiente "decisión sobre la prueba" (o decisión sobre qué proposiciones se tienen por probadas). Así, por ejemplo, una persona podría ser injustamente condenada en razón de la validación, por parte del tribunal, de la (compleja) hipótesis fáctica de cuya corroboración dependería la justicia sustantiva de esa condena, siendo esa hipótesis en efecto falsa, habiendo el tribunal tenido por no probada una proposición (verdadera) que fundamentaba la operatividad de una eximente determinada. De acuerdo con la concepción más extendida, este sería un caso de un "falso positivo", al haber sido tenida por verdadera una hipótesis condenatoria en efecto falsa, a pesar de que para que esta haya sido tenida por verdadera fuera necesario que no se tuviera por verdadera la proposición cuya verificación habría resultado en la aplicación de la eximente. Para un claro reconocimiento de este aspecto del discurso acerca de los falsos positivos y los falsos negativos, véase LETELIER (2018), p. 212.
} 
de significación penal ${ }^{36}$. El único fundamento plausible para este sesgo jurídico-penal se encuentra en la propia fisonomía del principio de culpabilidad en cuanto estándar sustantivo de justicia, bajo el cual "la pena no puede ser legitimada como resultado de una mera ponderación de intereses, sino sólo con la consideración de que el ciudadano se ha hecho merecedor de la restricción de sus derechos precisamente intencionada a través de la punición" ${ }^{37}$. Esto quiere decir que el principio de culpabilidad no funciona como un estándar de justicia distributiva, sino más bien como un estándar de justicia retributiva, con arreglo al cual la legitimación del reproche jurídico de culpabilidad materializado en la respectiva reacción punitiva depende críticamente de la sustentación de un juicio de merecimiento personalizado ${ }^{38}$. De ahí que la punición de un inocente resulte retributivamente insoportable en un sentido en que la falta de punición de un culpable no lo es, precisamente porque (solo) en el primer caso llega a materializarse una reacción cuya injusticia retributiva la vuelve teleológicamente inauténtica ${ }^{39}$.

Es fácil comprobar que el modelo procesal penal establecido en el CPP se encuentra codeterminado por semejante principio de valoración asimétrica, si el foco se pone en el estándar de prueba formulado en el art. 340. Pues este hace suficiente la existencia de una "duda razonable" acerca de la verdad de las premisas fácticas de una posible decisión de condena para la absolución del acusado ${ }^{40}$. A este respecto, es ilustrativo el contraste con aquellos modelos de proceso civil sometidos a un sistema de libre valoración de la prueba, que tienden a hacer suyo un estándar que, como el de la así llamada "preponderancia de evidencia", se distingue por expresar una valoración simétrica del riesgo de injusticia de la decisión consistente en acoger o rechazar la pretensión del demandante ${ }^{41}$.

\footnotetext{
${ }^{36}$ Acertadamente FRISTER (2016), pp. 153 y ss.; véase también FERRER (2007), pp. 139 y ss. Acerca de lo insostenible de la tradicional postulación de un "principio de subsidiariedad" de la intervención penal, asociada a la caracterización de esta como una pretendida ultima ratio regulativa, véase SEHER (2006), pp. 71 y ss., 75 y ss.

${ }^{37}$ FRISTER (2016), p. 154.

38 Véase ya NEUMANN (1989), p. 53. En detalle, MAÑALICH (2018), pp. 38 y ss., 45 y ss. Acerca de la irreductibilidad de la justificación retributiva de la punición a su eventual justificación distributiva, véase MAÑALICH (2014a), pp. 391 y ss., 401 y ss., 407 y ss. Ello se ve reflejado en el hecho de que ya la sola condena de un inocente irrogue a este un menoscabo que es definitorio del contenido de injusto (objetivo) del delito de calumnia, sin que un menoscabo de esa índole sea irrogado a persona alguna cuando tiene lugar la absolución de un culpable.

${ }^{39}$ Un desconocimiento de la asimetría así perfilada subyace al argumento a través del cual Oliver pretende sustentar la tesis de que, tanto bajo el derecho español como bajo el derecho chileno, el fundamento de una posible revisión lo proveería el principio de proporcionalidad en su dimensión de "prohibición de exceso"; véase OLIVER (2007), pp. 407 y ss., quien hace descansar críticamente esa tesis en la sugerencia de la falta de plausibilidad de invocar el principio de culpabilidad como estándar sustantivo de justicia como fun damento "si no se permite la revisión de absoluciones", pues esto determinaría que "pued[a]n existir muy injustas sentencias absolutorias firmes inalterables en el tiempo". Esto supone pasar por alto que la manera en que el principio de culpabilidad funciona como estándar de justicia del resultado del proceso lo vuelve compatible con el principio de valoración asimétrica del riesgo de una decisión (retributivamente) injusta.

${ }^{40} \mathrm{Al}$ respecto VALENZUELA (2017), pp. 85 y ss., 94 y ss. Acerca de la genealogía del estándar en el contexto de la tradición del common law, así como de las difícilmente superables objeciones dirigidas en contra de su viabilidad como parámetro de decisión intersubjetivamente controlable, véase LAUDAN (2006), pp. 30 y ss. En cuanto a los inconvenientes asociados a la adopción de una interpretación subjetivista del estándar de prueba así formulado (favorecida por el tenor literal del art. 340 del CPP), véase DUCE Y RIEGO (2007), pp. 483 y ss., 497 y ss.; fundamental al respecto, ACCATINO (2011), pp. 489 y ss., 495 y ss., quien ha ofrecido una muy convincente propuesta de reconstrucción (moderadamente) racionalista de la formulación del estándar en cuestión, que en lo fundamental ll eva a "identificar [una] duda razonable con c ua lqui er duda sobre la ocurrencia del hecho punible o la participación culpable del acusado que pueda justificarse en defectos de las pruebas disponibles" (p. 503). Acerca de la inadecuación de la noción de convicción, así como de la noción más general de creencia, para identificar la especie de actitud proposicional que sería distintivamente atribuible a un juez o a los integrantes de un tribunal colegiado cuando se declara probada una determinada proposición a través del correspondiente enunciado probatorio, véase FERRER (2005), pp. 80 y ss., con referencias ulteriores; también BAYÓN (2009), pp. 25 y ss.; así como GONZÁLEZ (2011), pp. 125 y ss. Al respecto, véase más abajo, nota 55.

${ }^{41}$ Véase ACCATINO (2011), pp. 486 y ss.; fundamental al respecto, en el contexto de la discusión chilena, LARROUCAU (2012), pp. 789 y
} 
Precisamente el hecho de que los modelos de proceso civil tiendan a implementar semejante principio de valoración simétrica del riesgo de injusticia del resultado del proceso se muestra, en lo que aquí interesa, en que la regulación del mecanismo de la revisión plasmada en el Título XX del Libro III del Código de Procedimiento Civil (en adelante, "CPC") haga procedente, configurándose alguna de las cuatro causales establecidas en su art. 810, la anulación de una "sentencia firme", con total independencia de si esta hubiera favorecido al demandante o al demandado. El hecho de que, en lugar de una solución simétrica, el CPP haga suya una solución asimétrica, determinante de la restricción del ámbito de operatividad del mecanismo de revisión a la posible anulación de sentencias condenatorias, es indicativo de una preocupación estandarizada ante la eventualidad de que llegue a adquirir fuerza de cosa juzgada una sentencia injustamente condenatoria ${ }^{42}$.

\subsection{La fisonomía de la revisión bajo el principio de valoración asimétrica}

La magnitud de esta preocupación hace posible explicar satisfactoriamente dos ulteriores datos de la regulación de la acción de revisión bajo el CPP. Por una parte, el art. 474 dispone que la revisión de una sentencia condenatoria puede ser solicitada "en cualquier tiempo", no quedando el ejercicio de la acción, en consecuencia, sometido a plazo de prescripción alguno ${ }^{43}$. Esto contrasta manifiestamente con la regulación del CPC, que sujeta la revisión de una sentencia firme al plazo de un año desde la notificación de la sentencia de cuya revisión se trata, según lo establece su art. 811. Por otra parte, es altamente significativo que el art. 474 del CPP, ya referido, reconozca legitimación activa al Ministerio Público para ejercer la acción de revisión. Pues esto significa que la preocupación asimétricamente unilateral por el riesgo de que sea ejecutada una sentencia injustamente condenatoria queda internamente conectada con el sometimiento de la persecución penal pública al así llamado "principio de objetividad", consagrado en el art. 3ำ de la Ley Orgánica Constitucional del Ministerio Público. En congruencia con lo dispuesto en el art. 3 del CPP, que obliga al Ministerio Público a orientar la investigación - cuya dirección le compete- no solo a la comprobación de "los hechos constitutivos de delito" y "los que determinen la participación punible", sino también a la comprobación de aquellos "que acreditaren la inocencia del imputado", el principio de objetividad expresa el compromiso del Estado, qua Estado de derecho, en cuanto a que el interés público en la persecución penal solo admite concretarse en la pretensión de que quien es efectivamente culpable del respectivo hecho punible sea condenado como responsable de este. Esto quiere decir que el

ss., quien defiende una propuesta diferenciadora, en atención a las particularidades de determinadas clases de asuntos litigiosos, que harían adecuada una alteración del estándar en cuestión. Para su institucionalización como el estándar de prueba que ha de regir, por defecto, en el ámbito del derecho administrativo sancionatorio, véase LETELIER (2018), pp. 216 y ss., 222 y ss., enfatizando su estatus como estándar "epistémicamente óptimo". Como ha mostrado BAYÓN (2009), p. 24, se trata aquí de un estándar que resulta ser "mínimamente sensible a la distribución del riesgo de error", que "no corrige [...] la asignación del mismo que resultaría de tener por probada la hipótesis con un grado de confirmación más alto, pero al menos dirime (no aleatoriamente) qué parte está llamada a soportar el riesgo de error cuando las hipótesis rivales tienen el mismo grado de confirmación", en la medida en que se vea complementado por "las correspondientes reglas sobre la carga de la prueba".

42 No está de más observar que el argumento así delineado para explicar la heterogeneidad de los regímenes de la revisión civil y la revisión penal, determinada por la valoración respectivamente simétrica y asimétrica del riesgo de un resultado sustantiva mente injusto, se encuentra en las antípodas de las disquisiciones con las que Carnelutti pretendía sustentar su "aversión [...] a la cosa juzgada penal", que él no vacilaba en cifrar en su "convicción de que el delincuente es un enfermo"; así CARNELUTTI (1961), p. 275, quien al mismo tiempo creía reconocer en "aquella concepción de la pena fríamente retributiva que es la máscara seudocientífica de la venganza" el genuino fundamento de "la pretendida intangibilidad de la cosa juzgada penal" (p. 280).

${ }^{43}$ Esto evoca a BINDING (1915), p. 296, quien observaba que "la admisión de la revisión [Wiederaufnahme], tal como ella se encuentra configurada de lege lata, contradice en considerable mayor medida el basamento conceptual de la prescripción que el principio de la cosa juzgada". 
Estado, qua Estado de derecho, no reclama tener interés alguno en la condena de quien no es culpable del hecho punible que se le imputa. De ahí que, como observara Binding, el propio Estado tenga que encontrarse habilitado para exigir, a través de sus propios órganos, la correspondiente revisión de la condena infundada in honorem justitiae immaculatae ${ }^{44}$.

La acción de revisión se presenta, desde este punto de vista, como un mecanismo de anulación de sentencias condenatorias cuya injusticia es sobrevinientemente detectada, lo cual quiere decir: cuya injusticia es detectada después de que la sentencia en cuestión haya adquirido fuerza de cosa juzgada, esto es, una vez que se ha vuelto "firme" y así susceptible de ejecución ${ }^{45}$. Pero ahora es necesario volver sobre la sugerencia de que bajo la regulación del CPP la revisión de una sentencia condenatoria no solo resulta procedente cuando la injusticia sobrevinientemente detectada consiste en la falta de satisfacción del criterio sustantivo de justicia provisto por el principio de culpabilidad. Antes bien, bajo ciertas condiciones una revisión también es procedente si se constata que la sentencia condenatoria en cuestión exhibe un déficit de justicia procedimental - esto es, la falta de satisfacción de algún estándar de corrección procedimental orientado a minimizar la probabilidad de que el resultado del proceso no satisfaga el criterio sustantivo de justicia provisto por el principio de culpabilidad-, revestido de una significación que justifica un desconocimiento retrospectivo de la fuerza de cosa juzgada ya adquirida por la decisión condenatoria ${ }^{46}$.

Esto hace posible proponer una clasificación de las causales de revisión enunciadas en el art. 473 del CPP, construida a partir de la distinción entre condenas sustantivamente injustas y condenas procedimentalmente injustas ${ }^{47}$. Como habrá de mostrarse a continuación, una implicación fundamental de esta distinción consiste en que la operatividad de las causales de revisión indicativas de un déficit de justicia procedimental no dependa de la comprobación de la inocencia del condenado, precisamente porque lo que fundamenta semejante revisión no es la constatación de la falta de satisfacción del principio de culpabilidad qua criterio sustantivo de justicia.

\section{Una reconstrucción sistemática de las causales de revisión}

\subsection{Una taxonomía de las causales de revisión}

Sobre la base de la distinción precedentemente presentada, las cinco causales de revisión previstas en el art. 473 del CPP se dejan sistematizar como sigue:

\begin{tabular}{|c|c|c|c|}
\hline $\begin{array}{c}\text { Forma de } \\
\text { injusticia }\end{array}$ & $\begin{array}{c}\text { Fundamento según } \\
\text { estándar quebrantado }\end{array}$ & $\begin{array}{c}\text { Fundamento según fisonomía } \\
\text { de causal }\end{array}$ & $\begin{array}{c}\text { Literal de } \\
\text { art. 473 }\end{array}$ \\
\hline & & Inocencia lógicamente inferida & b) \\
\hline
\end{tabular}

\footnotetext{
${ }_{44}$ BINDING (1915), p. 296, aun cuando restringiendo la tesis a aquellas causales de revisión relativas a la producción delictiva de la sentencia; al respecto, véase más abajo, 4.2 .

${ }^{45}$ Véase FERRER (2005), pp. 58 y ss.

${ }^{46}$ Debería ser obvio, con todo, que la preocupación institucionalizada por la eventualidad de una condena sustantivamente injusta no logra alcanzar una magnitud tal que haga procesalmente inaceptable, sin más, la posibilidad de que un proceso penal cualquier a culmine en la condena de un inocente. Pues la única manera de implementar institucionalmente una preocupación así perfilada consistiría en desconocer, sin más, la fuerza de cosa juzgada (negativa) de toda sentencia penalmente condenatoria. Acertadamente en este sentido, STUCKENBERG (1998), pp. 440 y ss., nota 11; coincidentemente, DUCE Y RIEGO (2007), p. 496.

${ }^{47}$ Para una distinción correspondiente en referencia a la operatividad de la Wiederaufnahme, bajo la StPO, a favor del acusado, véase GRECO (2015), pp. 901 y ss., 938 y ss.
} 


\begin{tabular}{|c|c|c|c|}
\hline $\begin{array}{c}\text { Injusticia } \\
\text { sustantiva }\end{array}$ & $\begin{array}{c}\text { Falsedad de premisa fáctica } \\
\text { de sentencia condenatoria }\end{array}$ & $\begin{array}{c}\text { Inocencia positivamente } \\
\text { demostrada }\end{array}$ & d) \\
\hline \multirow{2}{*}{$\begin{array}{c}\text { Injusticia } \\
\text { procediment } \\
\text { al }\end{array}$} & $\begin{array}{c}\text { Inconsistencia sistémica de } \\
\text { sentencias condenatorias }\end{array}$ & $\begin{array}{c}\text { Inadmisibilidad relacional de } \\
\text { condena bajo in dubio pro reo }\end{array}$ & a) \\
\cline { 2 - 4 } & $\begin{array}{c}\text { Condicionamiento delictivo } \\
\text { de sentencia condenatoria }\end{array}$ & $\begin{array}{c}\text { Condicionamiento delictivo de } \\
\text { formación de premisa fáctica }\end{array}$ & c) \\
\cline { 3 - 4 } & $\begin{array}{c}\text { Condicionamiento delictivo de } \\
\text { decisión de condena }\end{array}$ & e) \\
\hline
\end{tabular}

La aplicación del criterio clasificatorio ya introducido, referido a la naturaleza sustantiva o procedimental de la forma de injusticia que afecta a la sentencia condenatoria susceptible de revisión, lleva a una primera distribución de las cinco causales en dos grupos ${ }^{48}$.

\subsection{La revisión de una sentencia condenatoria fundada en su injusticia sustantiva}

Las causales establecidas en las letras b) y d) del art. 473 admiten ser conjuntamente agrupadas, en razón de que ambas descansan en la comprobación de la falta de culpabilidad del condenado en relación con el hecho punible que le fuera imputado. La diferencia específica que se da entre ellas concierne únicamente a la manera a través de la cual tiene lugar la comprobación de la inocencia de quien ha sido, en tal medida, injustamente condenado. Mientras la letra d) exige que "ocurriere algún hecho o apareciere algún documento desconocido durante el proceso, que fuere de tal naturaleza que bastare para establecer la inocencia del condenado", la letra b) exige que se compruebe que la supuesta víctima del pretendido homicidio (consumado) haya estado viva "después de la fecha en que la sentencia la [supuso] fallecida", lo cual hace posible inferir la imposibilidad de que haya sido perpetrado el homicidio (consumado) cuya imputación dio lugar a la condena así anulada ${ }^{49}$.

En tal medida, la causal de la letra b) no es sino un sub-caso (genérico) del caso (genérico) constitutivo de la causal de la letra d). Pues la comprobación de que la pretendida víctima del homicidio en cuestión se haya encontrado con vida más allá del punto de tiempo en que fuera (erróneamente) datada su muerte, no es más que la constatación de un hecho, que no pudo sino ser desconocido en el contexto del proceso respectivo, suficiente para tener por demostrada, por implicación, la falta de culpabilidad del condenado en relación con el hecho por el cual fuera condenado. Con todo, y simplemente para dar cuenta de la explícita diferenciación legal de ambas causales, puede distinguírselas en función de la singular estructura inferencial de la comprobación

\footnotetext{
$\overline{48}$ La premisa sobre la cual descansa la clasificación aquí propuesta, consistente en la distinción entre la injusticia sustantiva y la injusticia procedimental que puede afectar a la sentencia revisada, implica el rechazo de lo que, acertadamente, FERNÁNDEZ Y OLAVARRÍA (2018), pp. 1200 y ss., denuncian como el "modelo disyuntivo" de la revisión, bajo el cual el tribunal de revisión estaría siempre so metido a la disyuntiva de o bien rechazar la acción o bien declarar la inocencia del condenado. Una clasificación sumamente próxima a la aquí presentada fue propuesta por BINDING (1915), pp. 294 y ss., quien distinguía las siguientes tres constelaciones: a) la perpetración, en el marco del "juicio principal”, de una acción punible con incidencia en el pronunciamiento del juzgamiento; b) la coexistencia de múltiples imposiciones de pena incompatibles entre sí, referidas a un mismo caso; y c) el descubrimiento de nuevos hechos o medios de prueba que vuelvan dubitable el fundamento o la justicia del juzgamiento ya emitido. La clasificación aquí propuesta se diferencia de la sugerida por Binding, desde ya, por la circunstancia de que ella agrupa conjuntamente las causales (parcialmente) correspondientes a las dos primeras constelaciones identificadas por Binding.

${ }^{49}$ Tal reformulación de la causal resulta impuesta por su puesta en relación con la regla establecida en el inc. 2ㅇ del art. 475 del CPP, que condiciona la admisibilidad de la revisión así fundada a que la solicitud indique "los medios con que se intentare probar que la persona víctima del pretendido homicidio hubiere vivido después de la fecha en que la sentencia la supone fallecida".
} 
de la inocencia del condenado bajo la letra b), en contraste con la amplitud de los modos a través de los cuales puede tener lugar tal comprobación en los términos de la letra d).

Tratándose de esta última causal, puede ser importante clarificar el sentido y alcance de la exigencia de que "ocurriere o se descubriere algún hecho o apareciere algún documento desconocido durante el proceso" suficiente para "establecer la inocencia del condenado" ${ }^{50}$. Más allá de la terminología empleada en su formulación ${ }^{51}$, la operatividad de la causal depende de la corroboración de una hipótesis absolutoria que se apoye en uno o más elementos de juicio que hayan sido desconocidos en el marco del proceso resultante en la decisión de condena. Esto quiere decir, más precisamente, que los elementos de juicio en cuestión no deben pertenecer al subconjunto del conjunto de todos los elementos de juicio disponibles, conformado por aquellos elementos que hubieran sido aportados $y$ admitidos en el proceso en cuestión, esto es, al conjunto de los elementos de juicio "incorporados al expediente judicial" 52 . Precisamente en este sentido se ha pronunciado el Tribunal Constitucional Federal alemán al interpretar la exigencia, formulada en el numeral 5o del $\S 359$ de la StPO, de que sean "presentados nuevos hechos o medios de prueba" que sean aptos para fundar la absolución o una punición menos severa del condenado (o bien una

\footnotetext{
50 Sobre la manera en que la Corte Suprema ha tendido a interpretar la exigencia en cuestión, véase FERNÁNDEZ Y OLAVARRÍA (2009), pp. 222 y ss.; FERNÁNDEZ Y OLAVARRÍA (2018), pp. 1219 y ss.

${ }^{51}$ La terminología legislativa es conceptualmente desafortunada. Pues si -como debería ser el caso en el contexto del razonamiento probatorio- por "hecho" se entiende o bien un estado de cosas efectivamente existente, o bien una proposición verdadera, es claro que un hecho no es algo que pueda "ocurrir"; inclinado a validar la jerga de la "ocurrencia de hechos" se muestra, empero, FERRER (2005), p. 25; FERRER (2007), pp. 32 y ss. En general acerca del estatus ontológico de los hechos, véase MAÑALICH (2014b), pp. 52 y ss., con múltiples referencias ulteriores. Nótese que, en atención a la conexión analítica postulada entre las nociones de hecho y verdad, se vuelve necesario abandonar la jerga, enteramente generalizada en la literatura especializada, según la cual la actividad probatoria podría ser identificada con la "prueba de los hechos"; véase por ejemplo GONZÁLEZ (2011), pp. 106 y ss.; también COLOMA (2017), pp. 83 y ss., quien propone, empero, una definición (radicalmente funcionalista) de "hecho" como término que designaría una determinada clase de "artefacto lingüístico". Si se sostiene, por una parte, que no existe una conexión analítica (o "conceptual") entre las nociones de hecho y prueba, en términos tales que de la circunstancia de que haya sido probado que $p$ no se sigue que sea verdad que $p$-así acertadamente FERRER (2005), pp. 27 y ss., 35 y ss., 68 y ss. -, y se advierte, por otra, que un hecho no es sino una proposición verdadera, entonces no es necesariamente el caso que la prueba de $p$ se corresponda con la comprobación de un hecho constituido por la verdad de $p$, precisamente porque la prueba de $p$ no implica la verdad de $p$; de ahí que, en contra de lo sugerido por CARBONELL (2017), p. 7, no sea posible reformular la afirmación de que el estándar de "corrección epistémica" de una decisión judicial, en lo tocante a la corroboración de un enunciado determinado, se ve satisfecho, como la afirmación de que el enunciado en cuestión es verdadero. El problema ha sido muy exactamente advertido por VALENZUELA (2017), p. 28, aun cuando sin llegar a transformar este hallazgo en la premisa para una estipulación terminológica que evite sistemáticamente la inconveniente tematización de una "prueba de los hechos".

52 En general acerca de esta especificación procesal de los elementos de juicio constitutivos del conjunto de pruebas en relación con el cual han de entenderse formulados los enunciados probatorios, que en tal medida exhiben un carácter distintivamente relacional, véase FERRER (2007), pp. 40 y ss., quien sintetiza el criterio de identificación del conjunto en cuestión a través de la máxima quid non est in actis non est in mundo (en el contexto de la cual, como es obvio, la noción de mundo resulta epistémicamente cualificada, en el sentido de la configuración del mundo que "al interior del proceso" se tiene por existente); al respecto, véase ya BINDING (1915), pp. 272 y 279. En detalle acerca del estatus de los enunciados probatorios como enunciados relacionales, véase FERRER (2005), pp. 35 y ss. Que la fuerza ilocutiva de tales enunciados probatorios sea asertiva - o en la terminología (menos afortunada) favorecida por FERRER (2005), pp. 25 y ss., "descriptiva" -, de manera tal que ellos sean susceptibles de ser verdaderos o falsos, determina que el hecho de que en relación con el correspondiente conjunto de elementos de juicio esté probado que $p$ no es reducible al hecho de que el tribunal respectivo, sobre la base de ese mismo conjunto de elementos de juicio, haya tenido por probado que $p$. En contra de lo sugerido por DEI VECCHI (2014), pp. 254 y ss., no tiene sentido alguno negar el carácter asertivo de los enunciados probatorios, para atribuirles, en cambio, el carácter de enunciados constitutivos, y al mismo tiempo insistir en que el tribunal podría "haberse "equivocado» precisamente en "constituir» que "está probado que $p »$ " (p. 256). Si, como sostiene Dei Vechi, es conceptualmente inteligible que pueda tener lugar "la revocación de "está probado que $p$ »" a partir de la detección sobreviniente del error en que pudo haber incurrido el juzgador al tener por probado que $p$, de manera que pueda decirse, retrospectivamente, que a pesar de ello no estaba probado que $p$, ello depende de que el enunciado probatorio validado por la sentencia posteriormente impugnada o revisada pueda resultar verdadero o falso. Por lo demás, la tesis según la cual los enunciados probatorios no podrían exhibir fuerza asertiva, en razón del carácter irreductiblemente evaluativo del reconocimiento de la suficiencia de los correspondientes elementos de juicio en el contexto de una regulación procesal que haga suyo el "sistema de la sana crítica racional" (pp. 248 y ss.), se muestra comprometida con la validación de la así llamada "dicotomía hecho/valor", que constituye un muy problemático resabio de la epistemología asociada al empirismo lógico; sobre lo insostenible de tal dicotomía, véase PUTNAM (2002), pp. 7 y ss., 28 y ss.
} 
"decisión esencialmente distinta acerca de una medida de corrección o aseguramiento"), declarando que "[n]uevo es por principio todo aquello que no ha servido de base a la formación de la convicción del tribunal, aun si pudiera haberle servido de base" ${ }^{53}$.

La consideración de un pronunciamiento de la Corte Suprema que data de comienzos de la presente década puede ilustrar el carácter desconocido que ha de exhibir un "hecho", en cuanto elemento de juicio, para servir de base a la validación de una hipótesis absolutoria que no haya podido ser apoyada en el conjunto de elementos de juicio sobre la base de los cuales fuera pronunciada la sentencia condenatoria susceptible de revisión ${ }^{54}$. En el caso en cuestión, la corte acogió una acción de revisión interpuesta contra la sentencia condenatoria pronunciada contra un hombre declarado culpable de haber violado a su hija, siendo esta menor de 14 años. La revisión de la sentencia se fundó en una declaración jurada, emitida por la hija una vez adquirida la mayoría de edad, por la cual esta reconoció haber mentido al declarar, en el proceso que resultó en la condena, que había sido accedida carnalmente por su padre. Aquí es crucial que el carácter desconocido del elemento de juicio constituido por la declaración haya sido afirmado por la corte con independencia de que ella hubiera sido emitida con posterioridad a que la sentencia condenatoria en cuestión adquiriese fuerza de cosa juzgada. Decisivo fue, más bien, que ese elemento de juicio no hubiese quedado incorporado al conjunto de elementos de juicio sobre cuya base el tribunal validó la hipótesis condenatoria al pronunciar la sentencia revisada ${ }^{55}$.

Que la causal de la letra d) del art. 473 exija la validación de una hipótesis absolutoria, determina que su operatividad quede condicionada por la aceptación, por parte de la Corte Suprema qua tribunal de revisión, de las proposiciones que constituyen esa misma hipótesis absolutoria. Esto plantea, como es obvio, la pregunta acerca del estándar de prueba de cuya satisfacción depende que esas proposiciones puedan justificadamente declararse probadas. El estándar de prueba establecido en el art. 340 del CPP es indicativo de un compromiso con el principio de la valoración asimétrica del riesgo de una decisión sustantivamente injusta, en términos tales que ese estándar expresa una valoración del riesgo de una condena de quien es inocente (de aquello que se le imputara) como más grave, y así menos soportable, que el riesgo de una absolución de quien es culpable ${ }^{56}$. Esto basta para advertir que el estándar de prueba allí establecido, de cuya satisfacción depende la justificación procesal de una decisión de condena, no tiene pertinencia para la justificación procesal de una decisión de absolución ${ }^{57}$. Antes bien, y en atención a que se trata del estándar epistémicamente óptimo para la realización de la función procesal de "averiguación de la verdad" 58 , es enteramente plausible asumir que sea el estándar de prueba de la preponderancia de evidencia aquel al cual deba someterse la validación de la correspondiente hipótesis absolutoria ${ }^{59}$.

\footnotetext{
${ }^{53}$ BVerfG, decisión del 14.09.2006 - 2 BvR 123/06, 2 BvR 429/06, 2 BvR 430/06, en el fundamento B.I.3. Sobre el problema, véase GRECO (2015), pp. 917 ss.

${ }^{54}$ Corte Suprema, Rol № 2827-2011, de 28 de julio de 2011.

55 Véase FERNÁNDEZ Y OLAVARRÍA (2018), pp. 1219 y ss. Nótese que la noción de validación de la correspondiente hipótesis (inculpatoria o absolutoria), aquí empleada, puede ser definida a través de la noción más básica de "aceptación", favorecida por Ferrer para identificar la especie de actitud proposicional que sería atribuible a un órgano juzgador que declara probada una proposición cualquiera; véase FERRER (2005), pp. 90 y ss. Sobre esta base, por "validación" de la hipótesis en cuestión cabe entender la aceptación autoritativa del conjunto de proposiciones que la constituyen.

${ }^{56}$ Véase más arriba, 3.1.

${ }^{57}$ Véase FERRER (2007), pp. 141 y 152.

${ }^{58}$ Esto es, la finalidad de que sean declaradas probabas proposiciones que en efecto (y con independencia de ser declaradas probadas) resulten ser verdaderas; véase FERRER (2007), pp. 29 y ss.
} 


\subsection{La revisión de una sentencia condenatoria fundada en su injusticia procedimental}

Las tres causales restantes tienen en común, por contraste, que ellas involucran alguna forma -especialmente grave- de injusticia procedimental, sea en el pronunciamiento mismo de la sentencia condenatoria revisada, sea en el desarrollo del proceso resultante en su pronunciamiento, sin que la detección de la vulneración del respectivo estándar de justicia procedimental entrañe la constatación de la posible injusticia sustantiva de la decisión de condena. Según ya se anticipara, la gravedad específica de la correspondiente forma de injusticia procedimental necesita ser identificada con la magnitud de la sospecha que la correspondiente incorrección procedimental in abstracto sustenta en cuanto a la eventual injusticia sustantiva de la decisión de condena, en términos tales que la preservación de la fuerza de cosa juzgada de esta se vuelva jurídicamente insoportable ${ }^{60}$. Una implicación fundamental de esto último consiste en que la revisión fundamentada en cualquiera de las tres causales ahora consideradas no dependa de la validación de hipótesis absolutoria alguna.

En tal medida, se trata aquí de causales cuyo común denominador consiste en que la procedencia de la anulación de la sentencia revistada tiene lugar en razón de la detección sobreviniente de la vulneración especialmente grave de un estándar de justicia procedimental cuya observancia debería minimizar el riesgo de que el proceso respectivo culmine en una decisión sustantivamente injusta ${ }^{61}$. Sobre el trasfondo de esta caracterización genérica, la diferencia específica que define la fisonomía de cada una de estas tres causales queda determinada por el estándar de corrección procedimental que resulta contravenido en cada uno de los respectivos tres casos (genéricos).

La causal de la letra a) se hace operativa en virtud de la constatación de que se encuentran "sufriendo condena dos o más personas por un mismo delito que no hubiere podido ser cometido más que por una sola", lo cual determina que, con arreglo al pleonasmo expresado en la misma disposición, las dos o más sentencias así pronunciadas resulten ser "contradictorias". Que el estándar así vulnerado no puede identificarse con el criterio sustantivo de justicia provisto por el principio de culpabilidad, se sigue de que la satisfacción de los presupuestos de aplicación de la letra a) no implica de manera alguna la comprobación de la falta de culpabilidad del condenado en referencia al hecho por el cual se lo condenara. Antes bien, el déficit de justicia aquí involucrado tiene que ser identificado con la vulneración de un estándar procedimental, concerniente a la administración de la incertidumbre relativa a la verdad o falsedad de la premisa fáctica en la que se sustentara la decisión de condena ${ }^{62}$, a saber: la regla de decisión expresada en el aforismo in dubio

\footnotetext{
${ }^{59}$ Acerca del estatus del estándar de la preponderancia de evidencia como "estándar supletorio", véase ACCATINO (2011), pp. 487 y ss. De ahí que sea ése el estándar de prueba de cuya satisfacción debería depender, por ejemplo, que el respectivo tribunal de garantía declare "claramente establecida la inocencia del imputado", para así decretar el sobreseimiento definitivo de la causa con arreglo al art. 250 , letra b), del CPP.

60 Véase ya BINDING (1915), p. 296.

61 Véase más arriba, 2.3.

${ }^{62}$ Acerca de la significación del reconocimiento de la (irreductible) incertidumbre acerca de la satisfacción de las condiciones de aplicación de las reglas que conforman el (micro-)sistema jurídico prima facie aplicable a un caso como punto de partida para la institucionalización de todo modelo de proceso penal, véase ya BINDING (1915), pp. 268 y ss. Sobre la incidencia de ese reconocimiento, asociado a la adopción (a lo menos implícita) de una epistemología falibilista, en la reconstrucción del así llamado "derecho probatorio", véase VALENZUELA (2017), pp. 17 y ss. En general acerca de la epistemología del proceso penal como contexto de "epistemología aplicada", véase LAUDAN (2006), pp. 1 y ss., 4 y ss.
} 
pro reo ${ }^{63}$. La particularidad del caso (genérico) así regulado consiste en que esa incertidumbre no es interna al proceso que resultara en el pronunciamiento de la respectiva sentencia condenatoria, sino externa y más propiamente: relacional. Pues la incertidumbre en cuestión emerge recién a través de la puesta en relación de las dos o más sentencias que expresan decisiones de condena dirigidas contra personas diferentes en referencia a un mismo hecho punible, no susceptibles de ser conjuntamente pronunciadas en razón de que la concreta fisonomía del hecho punible particular por el cual fueran condenadas esas dos o más personas solo se muestra compatible con la hipótesis de que aquel fue perpetrado por una única persona ${ }^{64}$.

En otras palabras, la consideración conjunta de dos o más decisiones de condena pronunciadas contra personas diferentes por un hecho punible particular que solo pudo ser perpetrado por una única persona, activa una aplicación (retrospectiva) del in dubio pro reo a favor de cada una de las personas condenadas separadamente. Pues la consideración conjunta de las dos o más sentencias condenatorias logra retrospectivamente sustentar, respecto de cada una de las personas condenadas, una duda razonable acerca de la verdad de la premisa fáctica de la correspondiente decisión de condena ${ }^{65}$, en cuanto las dos o más sentencias condenatorias así pronunciadas no logran satisfacer un estándar de coherencia sistémica referido al universo de sentencias condenatorias que pueden ser jurídicamente reconocidas como compatibles bajo la vigencia del in dubio pro reo. De esto se sigue, aunque la regulación legal no lo haga explícito, que la anulación de la sentencia revisada tiene que extenderse, al mismo tiempo, a la o las restantes sentencias condenatorias que la Corte Suprema haya declarado contradictorias en relación con aquella ${ }^{66}$.

Por su parte, las dos causales restantes, establecidas en las letras c) y e) del art. 473, quedan definidas por la circunstancia de que ellas hacen procedente la revisión de una sentencia condenatoria en cuya generación procesal ha incidido el quebrantamiento de una norma de prohibición jurídico-penalmente reforzada, esto es, la realización de una determinada forma de comportamiento punible, lo cual necesita haber sido declarado por una sentencia judicial firme.

Desde esta perspectiva, la especificidad de la causal de la letra c) consiste en que la sentencia revisada se encuentre "fundada en un documento o en el testimonio de una o más personas, siempre que dicho documento o dicho testimonio hubiere sido declarado falso por sentencia firme en causa criminal". Esto quiere decir que en la fundamentación de la premisa fáctica incorporada al esquema de razonamiento judicial resultante en el pronunciamiento de la decisión de condena debe haber tenido incidencia o bien un documento cuya producción o alteración sea constitutiva de falsedad documental, o bien una declaración testimonial constitutiva de falso

\footnotetext{
63 Sobre la conexión entre el principio in dubio pro reo y la valoración asimétrica del riesgo de injusticia sustantiva del resultado del proceso, véase FRISTER (2016), pp. 152 y ss. Acerca de la dependencia del primero respecto del estándar de prueba que haga suyo el respectivo modelo procesal, véase más abajo, nota 75.

${ }^{64}$ Véase al respecto FERNÁNDEZ Y OLAVARRÍA (2018), pp. 1277 y ss., quienes no llegan a vincular la operatividad de la causal aquí considerada con el estándar del in dubio pro reo. Nótese que la pertinencia de una consideración conjunta de dos o más sentencias (condenatorias) no es privativa de la causal de revisión así configurada. Otra muestra de ello emerge, en un contexto enteramente distinto, en la mal llamada regla de "unificación de penas", establecida en el art. 164 del Código Orgánico de Tribunales. Sobre esto último, véase MAÑALICH (2018), pp. 121 y ss., 143 y ss.

${ }^{65}$ Como debería ser obvio, a través de la noción de "premisa fáctica" se identifica, stricto sensu, una determinada cadena de enunciados que fijan los resultados de las múltiples acciones probatorias que conjuntamente sustentan la enunciación del conjunto de proposiciones que el tribunal declara probadas; véase al respecto GONZÁLEZ (2011), pp. 105 y ss.; así como CARBONELL (2017), pp. 22 y ss., 28 y ss.

66 Tal como lo previera explícitamente el art. 662 del CdPP, en relación con la causal establecida en el № 1 de su art. 657 ; al respecto, y observando acertadamente que lo mismo ha de valer bajo la regulación del CPP, véase PAILLAS (2001), pp. 16 y ss.
} 
testimonio ${ }^{67}$. Por su parte, la causal de la letra e) da lugar a la revisión de una sentencia condenatoria "pronunciada a consecuencia de prevaricación o cohecho del juez que la hubiere dictado o de uno o más de los jueces que hubieren concurrido a su dictación, y cuya existencia hubiere sido declarada por sentencia judicial firme". Aquí se trata de que el pronunciamiento de la sentencia condenatoria como tal o bien ha conllevado una prevaricación, o bien se corresponde con la materialización de un servicio o prestación por la cual el o los jueces respectivos hubiesen solicitado o aceptado recibir un determinado beneficio, incurriendo así en alguna variante de cohecho ${ }^{68}$.

En relación con las últimas dos causales consideradas, cabe observar que el requisito de que la perpetración del hecho punible que ha incidido, probatoria o directamente, en el pronunciamiento de la decisión de condena haya sido judicialmente establecida por sentencia firme no supone que esta última sentencia necesariamente haya sido condenatoria. Antes bien, debe tenerse por suficiente que la realización (antijurídica) del correspondiente tipo-de-delito haya sido demostrada y declarada por la sentencia en cuestión, con independencia de si su imputación haya resultado o no en la condena de una o más personas. Pues desde el punto de vista de la injusticia procedimental exhibida por la sentencia condenatoria en cuyo pronunciamiento ha tenido incidencia el respectivo comportamiento delictivo, no cabe reconocer diferencia relevante alguna entre ambas situaciones.

Con todo, no está de más reparar en las implicaciones de que la injusticia procedimental exhibida por la sentencia revisada haya sido condicionada de un modo que fundamente, ulteriormente, la responsabilidad de quien ha incurrido en el comportamiento constitutivo de falso testimonio, falsedad documental, prevaricación o cohecho, por la injusta materialización de la reacción punitiva en la persona del condenado. En tal caso, la producción del menoscabo de los respectivos bienes jurídicos del condenado será imputable a quien haya incurrido en ello, a título de autoría mediata "por actuación justificada del instrumento" ${ }^{69}$, siempre que la producción de ese menoscabo tenga relevancia típica - verbigracia: a título de secuestro o de coacción- según cuál sea la naturaleza de la pena injustamente impuesta ${ }^{70}$.

\footnotetext{
${ }^{67}$ De acuerdo con lo establecido más arriba, nota 52, esa incidencia resulta constituida por la circunstancia de que, en cuanto elemento de juicio, el documento inauténtico o falso (según si la falsedad documental involucrada es de carácter ontológico o proposicional) o bien la declaración testimonial falsa, según corresponda, pertenezca al conjunto de elementos de juicio sobre cuya base haya sido pronunciada la sentencia condenatoria de cuya revisión se trata. En tal medida, la incidencia "probatoria" del documento o la declaración no necesita superar el umbral de relevancia que es propio de la forma de lesividad identificada con el peligro abstracto; específicamente en referencia a la estructura típica del falso testimonio como delito de peligro abstracto, véase WILENMANN (2014), pp. 100 y ss.

${ }^{68}$ Hasta el 20 de noviembre de 2018, entre las variantes de prevaricación (judicial), tipificadas en el $\S 4$ del Título V del Libro II del Código Penal (en adelante, “CP"), figuraba, según lo establecido en el № 2 del art. 223, la así llamada "prevaricación por cohecho"; véase al respecto, por todos, GARRIDO (2010), pp. 485 y ss. La modificación legislativa resultante en su supresión deja intacta, como es obvio, la aplicabilidad de las normas de sanción que tipifican las diversas modalidades "genéricas" de cohecho como delito contra la probidad en el ejercicio de una función pública, establecidas en los arts. 248, 248 bis y 249 del CP.

${ }^{69}$ La circunstancia de que el comportamiento de los funcionarios que por sí mismos dan lugar a la ejecución de la pena resulte objetivamente permisible (y en tal medida, "justificado"), determina que deba tenerse por excluida la fundamentación de un permiso por legítima defensa a favor de la eventual resistencia del condenado ejercida contra su padecimiento de la sanción; sobre el problema, véase ya BINDING (1915), pp. 284 y ss. En general sobre la estructura de esta variante de autoría mediata, véase MAÑALICH (2008), pp. 68 y ss.; MAÑALICH (2010b), pp. 404 y ss., con referencias ulteriores.

70 Para una muy lúcida consideración general del problema, véase ya BINDING (1915), pp. 290 y ss., quien a partir de la sustentación de semejante imputación al juez o los jueces prevaricadores de la producción del menoscabo punitivamente irrogado al condena do extraía la conclusión de que, "por principio", el correspondiente deber indemnizatorio no podría recaer sobre el Estado, sino solo so bre el o los jueces responsables. Como es obvio, que tal conclusión se siga o no depende, exclusivamente, de cómo se encuentre configurado el régimen jurídico de la responsabilidad ("extracontractual") del Estado por error judicial. Bajo el régimen de la revisión pla smado en el CPP, la procedencia de una acción indemnizatoria susceptible de ser ejercida contra el Estado sol o queda condicionada, según lo establece el inc. 3으 del art. 478, a que "hubiere mérito", lo cual, en los términos de la regla de la letra i) del № 7 del art. 19 de la Constitución Política de la República, se traduce en la exigencia de que la sentencia revisada y anulada sea calificada como "injustificadamente errónea o arbitraria".
} 


\section{Inocencia y clausura procesal}

\subsection{Inocencia como "negación interna" de culpabilidad}

Una caracterización exhaustiva de los presupuestos y las consecuencias de la operación del mecanismo de la revisión de sentencias penalmente condenatorias no puede prescindir del análisis de un problema que tiende a ser sistemáticamente pasado por alto. El problema se suscita en razón de que la regulación legal de la revisión hace uso de la expresión "inocencia" en tres contextos precisos, de los cuales aquí interesa considerar dos: por una parte, al establecer la causal de la letra d) art. 473, respecto de la cual - como ya se mostrara - la causal de la letra b) se comporta como un sub-caso (genérico); y por otra, al habilitar a la Corte Suprema para pronunciar, inmediatamente después, pero separadamente, de la anulación de la sentencia revisada, "la sentencia de reemplazo que corresponda" en caso de que "de los antecedentes resultare fehacientemente acreditada la inocencia del condenado", según dispone el inc. $2^{\circ}$ del art. $478^{71}$. El problema consiste en una doble ambigüedad que afecta al uso de la palabra "inocencia" en ambos contextos.

Una primera ambigüedad aquí relevante consiste en que, en la formulación del enunciado (relacional) que presenta el resultado de un proceso penal que ha concluido en el pronunciamiento de una sentencia absolutoria, la negación de la culpabilidad del acusado pueda asumir o bien la forma de una negación interna, o bien la forma de una negación externa ${ }^{72}$. Un enunciado de la primera clase sería aquel por el cual se afirmara la comprobación de la falta de culpabilidad del acusado en relación con aquello que se le imputara; un enunciado de la segunda clase, en cambio, sería aquel por el cual se afirmara la falta de comprobación de la culpabilidad del acusado. Es claro que, en cuanto enunciado procesal, slo una negación interna de la culpabilidad del acusado resulta lógicamente equivalente a la afirmación de su inocencia; una negación externa de su culpabilidad, en cambio, no admite semejante reformulación, en razón de que entre la aserción de la comprobación (procesal) de la culpabilidad del acusado y la aserción de la comprobación (procesal) de su falta de culpabilidad solo se da una relación de oposición contraria, y no de oposición contradictoria $^{73}$. De ahí que del hecho de que haya sido negada la comprobación de la culpabilidad del acusado no sea posible inferir que haya sido comprobada su falta de culpabilidad, esto es, su inocencia. En la terminología favorecida por Laudan, esto equivale a decir que la constatación (procesal) de la "inocencia probatoria" del acusado no implica una afirmación (procesal) de su "inocencia material" ${ }^{\prime 4}$.

La ambigüedad así detectada se ve procesalmente neutralizada, en la medida en que el non liquet resultante de que, bajo el correspondiente estándar de prueba, no haya resultado procesalmente comprobada la culpabilidad del acusado sea razón suficiente, en conformidad con la institucionalización de la presunción de inocencia como regla de decisión, expresada en el aforismo

\footnotetext{
${ }^{71}$ El tercer contexto lo representa el reconocimiento de la facultad del condenado, cuya "completa inocencia" hubiera sido comprobada ya sea por la propia Corte Suprema, ya sea por el tribunal ante el cual se hubiera desarrollado el "nuevo juicio", para exigir la publicación de la sentencia absolutoria en el Diario Oficial a costa del fisco, así como la devolución de las sumas que hubiera enterado "en razón de multas, costas e indemnización de perjuicios en cumplimiento de la sentencia anulada”, según lo previsto en el inc. 10 del art. 479.

72 Fundamental al respecto, y detalladamente, STUCKENBERG (1998), pp. 442 y ss.; véase también FERRER (2005), pp. 37 y ss.

${ }^{73}$ Así ya BINDING (1915), p. 346.

74 LAUDAN (2006), pp. 11 y ss., 96 y ss.; distinguiendo entre "inocencia sustantiva" e "inocencia procedimental", véase FINDLEY (2010), pp. 1194 y ss., 1205 y ss. Para una distinción similar, véase LASCURAín Y GASCÓN (2018), p. 12, aun cuando sobre la base de la muy problemática contraposición de las nociones de "verdad fáctica" y "verdad procesal". Una distinción solo parcialmente coincid ente con las precedentes es presentada por CASTILLO (2013), pp. 252 y ss., al contraponer las nociones de "inocencia fáctica" e "inocencia normativa", distinción asimismo asumida por FERNÁNDEZ Y OLAVARRÍA (2018), pp. 1205 y ss.
} 
in dubio pro reo, para el pronunciamiento de una sentencia absolutoria ${ }^{75}$. Pero ello no obsta a que advertir esa ambigüedad tenga importancia para la reconstrucción de la regulación legal de la revisión. Pues esta hace uso de las expresiones "inocencia" e "inocente" al formular reglas cuya condición de aplicación consiste en la comprobación procesal sobreviniente de la falta de culpabilidad del condenado, esto es, en una negación interna de su culpabilidad como enunciado alcanzado a través del proceso al que da lugar el ejercicio de la acción de revisión. Esto exige identificar el estándar de prueba que debe ser satisfecho para que esa falta de culpabilidad pueda ser procesalmente declarada. Según ya se sostuviera, este estándar de prueba no puede identificarse con el estándar que bajo el art. 340 del CPP condiciona la corroboración de una hipótesis condenatoria ${ }^{76}$, sino más bien con el estándar (menos exigente) de la preponderancia de evidencia ${ }^{77}$.

\subsection{Inocencia "extensional" versus inocencia "intensional"}

Pero hay una segunda ambigüedad que exhibe el uso de "inocencia", que resulta de la falta de diferenciación de dos sentidos en los cuales puede hablarse de la inocencia de una persona respecto de lo que pudiera serle imputable en el marco de un proceso cualquiera, a saber: un sentido "intensional" y un sentido "extensional".

Esta distinción se obtiene a partir de la distinción, más básica, entre el concepto de hecho en sentido jurídico-penal y el concepto de hecho en sentido procesal ${ }^{78}$. La noción jurídico-penal de hecho sirve para tematizar cualquier instancia particular de realización imputable de algún tipo-dehecho-punible, o bien de alguna forma de comportamiento derivativamente referida a la realización de un tipo-de-hecho-punible, entendida como el antecedente de la eventual imposición de una sanción constitutiva de pena ${ }^{79}$. Por su parte, la noción procesal de hecho hace posible identificar el complejo de circunstancias fácticas que conforman el objeto temático de un proceso cualquiera, y así el sustrato de lo que pudiera llegar a ser formalmente imputado al acusado, a través de lo cual quedan fijados tanto la extensión del efecto de cosa juzgada de la respectiva sentencia de término -y así también de la excepción de litispendencia- como el alcance de la exigencia de correlación (factual) entre sentencia y acusación impuesta por el principio de congruencia ${ }^{80}$. Aquí interesa sobre todo advertir que mientras la noción jurídico-penal de hecho se comporta como una categoría

\footnotetext{
75 Latamente al respecto STUCKENBERG (1998), pp. 469 y ss., 481 y ss.; al respecto, asimismo, KOTSOGLOU (2014), pp. 39 y ss. Esto muestra, de paso, que la operatividad del principio in dubio pro reo no es independiente de la formulación del correspondiente estándar de prueba. Pues solo en conformidad con este último puede determinarse qué cuenta, procesalmente, como una incertidumbre que haya de dar lugar a la materialización de las consecuencias jurídicas asociadas a la falta de corroboración de la hipótesis conden atoria. Véase FERRER (2012b), pp. 179 y ss., 181 y ss., quien a porta la crucial observación de que, en contra de lo que pudiera sostenerse -y como de hecho lo sostiene Kotsoglou-, la formulación de un estándar de prueba intersubjetivamente controlable no logra hacer superflua la tematización del in dubio pro reo como regla de decisión, en la medida en que esa formulación no logre eliminar íntegramente la potencial vaguedad del estándar del prueba, lo cual volvería "necesaria una regla de segundo orden, que establezca qué debe realizarse en caso de duda sobre el cumplimiento del estándar"; así FERRER (2012b), p. 183.

${ }^{76}$ Véase solo FERRER (2007), pp. 141 y 152.

77 Véase más arriba, nota 41. Esto exige advertir que, en contra de lo sugerido en FERNÁNDEZ Y OLAVARRÍA (2009), p. 241, así como en FERNÁNDEZ Y OLAVARRÍA (2018), pp. 1264 y ss., ni la letra d) del art. 473 ni el art. 478 del CPP formulan, en sentido propio, "estándar de prueba" alguno que deba satisfacer la declaración de la inocencia de la persona condenada por la sentencia revisada. Acerca de la falta de plausibilidad de identificar cláusulas similarmente vagas, contenidas en disposiciones de la Ley de Enjuiciamiento Criminal espa ñola, como formulaciones de estándares de prueba, véase FERRER (2007), pp. 141 y ss., nota 123.

78 Véase MAÑALICH (2018), pp. 77 y ss.

${ }^{79}$ Acerca del estatus de tales "formas de punibilidad derivativas", dependientes de las formas de comportamiento especificadas por los respectivos tipos-de-hecho-punible, véase MAÑALICH (2017), pp. 467 y ss., con especial referencia a la estructura de la tentativa.

${ }^{80}$ En referencia a los pormenores del derecho procesal penal chileno, véase solo DEL RíO (2009), pp. 131 y ss., 147 y ss.
} 
intensional, en el sentido de que la identidad de un hecho punible es siempre relativa a una determinada descripción - a saber: la descripción abstracta en la que consiste el correspondiente tipo-de-hecho-punible-, la noción procesal de hecho es, en cambio, una extensional, en el sentido de que el objeto temático del proceso en cuestión es insensible a la específica descripción - por lo demás, mutable a lo largo del desarrollo del proceso- que determina la calificación jurídica del sustrato de circunstancias fácticas que fijan lo que puede resultar definitivamente imputable al acusado $^{81}$.

Lo anterior hace posible detectar, entonces, una ambigüedad semántica involucrada en la afirmación de que una persona es inocente de aquello por lo cual fuera condenada. Pues aquello de lo cual el condenado pudiera ser inocente admite ser interpretado en clave intensional o en clave extensional: en el primer sentido, se trata de la inocencia del condenado frente al o los cargos por los cuales fuera efectivamente condenado; en el segundo sentido, en cambio, se trata de su inocencia frente a cualesquiera cargos que en principio pudieran haber estado referidos al complejo de circunstancias fácticas que conformaron el objeto temático del proceso resultante en la decisión de condena, con independencia de si esos cargos llegaron a ser formulados.

La distinción así obtenida contribuye a clarificar el sentido en que la inocencia del condenado debe ser comprobada para que se configure alguna de las dos causales de revisión que se fundan en la injusticia sustantiva de la condena, por un lado, así como el sentido en que la comprobación de la inocencia del condenado en el marco del respectivo proceso de revisión habilita a la Corte Suprema para pronunciar, inmediatamente tras la anulación de la sentencia condenatoria, la correspondiente sentencia absolutoria como sentencia de reemplazo, por otro ${ }^{82}$. En cuanto a lo primero, es claro que la inocencia cuya comprobación ha de conducir, en los términos de las causales de las letras b) y d) del art. 473 del CPP, a la invalidación de la respectiva sentencia condenatoria, debe ser entendida en el sentido de una inocencia intensional. Pues la específica incorrección de la sentencia revisada, en virtud de haber dado lugar a la condena de una persona en contra de quien no era sustantivamente procedente la correspondiente declaración de culpabilidad, es necesariamente relativa al pretendido hecho punible que fungiera como título de condena. Pero que como resultado del ejercicio exitoso de la acción de revisión sea declarada la inocencia intensional del condenado, en los términos así precisados, no es razón suficiente para que, sin más, el tribunal de revisión proceda a pronunciar una sentencia de reemplazo que declare la inocencia del condenado frente a cada uno de los posibles cargos susceptibles de ser fundados en las circunstancias que conformaron el objeto temático del proceso resultante en la sentencia revisada, esto es, que declare su inocencia en sentido extensional ${ }^{83}$. Que una y otra determinación son enteramente independientes entre sí, puede ser ilustrado a través de un ejemplo.

Asúmase que, a favor de quien hubiera sido ya condenado, por sentencia de término, como autor de un homicidio consumado, fuera interpuesta una acción de revisión fundada en la causal de la letra b) del art. 473, cuyo ejercicio resultara exitoso al lograr probarse que la supuesta víctima del pretendido homicidio estuvo con vida más allá del momento en que, de acuerdo con la sentencia condenatoria, habría tenido lugar su muerte. ¿Se seguiría de la anulación de la sentencia, por parte de la Corte Suprema, sobre la base de la comprobación de la inocencia del condenado frente al

\footnotetext{
${ }^{81} \mathrm{Al}$ respecto, MAÑALICH (2018), pp. 80 y ss., 89 y ss., 113 y ss., 117 y ss.

82 Acerca de la marcadísima tendencia de la Corte Suprema a desconocer la independencia recíproca de ambas determinaciones, véase FERNÁNDEZ Y OLAVARRÍA (2009), pp. 238 y ss.; FERNÁNDEZ Y OLAVARRÍA (2018), pp. 1201 y ss.

${ }^{83}$ El problema no es advertido por MOSQUERA Y MATURANA (2012), p. 592, en su referencia a las causales de las letras b) y d) del art. 657 del CdPP. Al respecto, véase FERNÁNDEZ Y OLAVARRÍA (2018), pp. 1250 y ss., 1256 y ss.
} 
cargo referido al pretendido homicidio consumado, que la corte debería entonces pronunciar una sentencia absolutoria en reemplazo de la sentencia revisada? La respuesta es negativa. Es obvio que la prueba de que la presunta víctima del homicidio en cuestión estuvo con vida más allá del punto de tiempo en que la sentencia condenatoria datara su supuesto fallecimiento basta para establecer que al condenado en efecto no resultaba imputable el homicidio consumado por el cual fuera declarado culpable. Pero esto deja intacta la posibilidad de que al condenado sea imputable un hecho punible distinto de ese homicidio consumado, eventualmente constituido por circunstancias asimismo conformantes del correspondiente hecho en sentido procesal, verbigracia, un homicidio frustrado o tentado respecto de la misma presunta víctima ${ }^{84}$. En tal situación, entonces, nada obstaría a que la Corte Suprema se abstuviera de pronunciar sentencia de reemplazo alguna, dejando abierta la posibilidad, indudablemente prevista en los arts. 479 y 480 del CPP, de que tenga lugar un nuevo proceso, en la medida en que el Ministerio Público se decida a ejercer la acción penal "por los mismos hechos sobre los cuales recayó la sentencia anulada", según dispone el inc. 1ํ del ya referido art. $480^{85}$.

Pero al mismo tiempo hay que observar que la independencia entre la causal por la cual es acogida la acción de revisión, por un lado, y el eventual pronunciamiento de una sentencia absolutoria de reemplazo por parte de la Corte Suprema, por otro, también opera en la dirección opuesta. Esto quiere decir que, aun cuando la causal de revisión exitosamente invocada sea una que descansa en una forma de injusticia procedimental - como lo son las de las letras a), c) y e) -, esto es, en una causal cuya invocación no depende de la alegación de la inocencia (intensional) del condenado, la corte podría decidirse a pronunciar, acto seguido, una sentencia absolutoria como sentencia de reemplazo, siempre que, según lo establecido en el inc. 20 del art. 478, "de los antecedentes resultare fehacientemente acreditada la inocencia del condenado". Que tal comprobación resulte "de los antecedentes" sobre los cuales haya descansado la anulación de la sentencia condenatoria, depende de que esos antecedentes logren, contingentemente, sustentar no solo la constatación del respectivo vicio de justicia procedimental, sino más allá de esto, y asimismo, la corroboración de una hipótesis absolutoria. Pero es fundamental no perder de vista que, en el contexto del ya mencionado inc. 20 del art. 478, la inocencia "fehacientemente acreditada" debe ser identificada con la inocencia extensional del condenado. Pues solo en tal caso se justifica que, a través de la correspondiente sentencia de reemplazo, la corte cierre la posibilidad procesal de una nueva persecución penal.

\subsection{Revisión, ne bis in idem y prescripción de la acción penal}

Lo anterior muestra que solo a partir de la explicitación de la distinción entre los dos sentidos en que cabe hablar de la inocencia de quien fuera - en tal medida - injustamente condenado es posible reconstruir adecuadamente la relación que se constituye entre el mecanismo de la revisión y el principio ne bis in idem, entendido este como un estándar de clausura procesal consistente en la prohibición de juzgamiento múltiple por un mismo hecho (en sentido extensional) ${ }^{86}$. Pues solo sobre la base de esa distinción, según ya se explicara, se dejan esclarecer las condiciones de las cuales depende que, tras la anulación de la sentencia condenatoria resultante

\footnotetext{
${ }^{84}$ Homicidio frustrado o tentado que, como tal, supondría la realización de la correspondiente "forma de punibilidad derivativa"; véase más arriba, nota 79.

${ }^{85}$ Como aquí ya FERNÁNDEZ Y OLAVARRÍA (2018), pp.1262 y ss. Véase más abajo, nota 87.

${ }^{86}$ Véase ya BENNECKE Y BELING (1900), p. 413. En detalle, MAÑALICH (2018), pp. 67 y ss., 96 y ss., 116 y ss.
} 
del acogimiento de la acción de revisión, resulte procedente el pronunciamiento de una sentencia de reemplazo que impida, en conformidad con el principio de persecución penal única consagrado en el art. 10 del CPP, la substanciación de un nuevo proceso referido a "un mismo hecho".

Esto significa que la sola anulación de la sentencia revisada no representa obstáculo alguno a la iniciación de una nueva persecución, según lo reconoce el ya referido art. 480 del CPP. Pues la anulación de una sentencia condenatoria, obtenida a través del ejercicio de la acción de revisión, se reduce a operar en la forma de una supresión ("extraordinaria") de su fuerza de cosa juzgada (material), lo cual priva de resolución definitiva al caso que fuera objeto del proceso resultante en la sentencia así anulada. En la medida en que el propio tribunal de revisión no proceda a remplazar esta sentencia de término por una sentencia diferente, la situación del favorecido por la decisión de revisión precisamente no será la de una "persona condenada, absuelta o sobreseída definitivamente por sentencia ejecutoriada", según reza el inc. 2o del art. 1어 del CPP, que pudiera así oponer la excepción de cosa juzgada ante la acción penal susceptible de ser nuevamente ejercida por el Ministerio Público ${ }^{87}$.

Que el principio ne bis in idem no resulte aplicable en cuanto regla de clausura procesal en aquellos casos en los cuales la decisión de revisión no va seguida del pronunciamiento de una sentencia de reemplazo, ciertamente no prejuzga, empero, si acaso otro mecanismo de clausura procesal pudiera resultar operativo. Este es precisamente el estatus de la prescripción de la acción penal, que delimita el horizonte temporal al interior del cual la persecución penal, en referencia a un posible hecho punible, resulta jurídicamente contingente ${ }^{88}$. Aquí únicamente interesa destacar el efecto que la anulación, vía revisión, de una sentencia condenatoria ha de tener en el cómputo del transcurso del plazo de prescripción de la acción penal susceptible de ser eventualmente ejercida por el Ministerio Público, con posterioridad a la anulación de la sentencia revisada.

El art. 96 del CP hace del ejercicio de la acción penal una causa de suspensión de la prescripción, añadiendo que, si "se termina sin condenarle", ha de tenerse por reanudado el transcurso del plazo correspondiente, como si no hubiese tenido lugar la suspensión en cuestión ${ }^{89}$. La anulación de una sentencia injustamente condenatoria a la que conduce el ejercicio exitoso de la acción de revisión lleva, según ya se observara, a la supresión de la fuerza de cosa juzgada de la sentencia condenatoria revisada. Esto quiere decir que, una vez anulada la sentencia revisada, quien hubiera sido condenado por ella se encontrará en una situación en la que el proceso seguido en su contra contará como uno que terminó "sin condenarle". Luego, que esa persona pueda exitosamente oponer la excepción de prescripción ante la acción penal que pudiera (volver a)

\footnotetext{
87 Esto es palmariamente pasado por alto por HORVITZ Y LÓPEZ (2004), pp. 456 y ss., donde se sostiene que "una formalización por los mismos hechos en contra del condenado cuya sentencia condenatoria se declaró nula es imposible, porque infringiría el principio de non bis in idem". Es especialmente llamativo que, en apoyo de esta toma de posición, se incluya una referencia a un antecedente de la discusión legislativa del proyecto del CPP, consistente en la "constancia" que habría sido dejada por el Senado en cuanto a que "[e]I ministerio público podrá iniciar o no otra acción, según la prueba de que disponga, salvo por el delito específico por el que ha sido absuelto" (p. 457). Contra lo sugerido por Horvitz y López, la inviabilidad de una nueva persecución aparece aquí referida a casos en los cuales haya sido pronunciada una sentencia absolutoria como sentencia de reemplazo. Hay que observar que, más allá de esto, el antecedente de la historia fidedigna del establecimiento de la disposición resulta en todo caso errático, dado que el pronunciamiento de la respectiva sentencia absolutoria en reemplazo de la sentencia revisada impide la activación de una persecución en referencia al correspondiente hecho procesal en su conjunto, y no solo en referencia al "delito específico por el cual [el previamente condenado] ha sido absuelto"; esto último también es pasado por alto por MOSQUERA Y MATURANA (2012), p. 593. Sobre esto último, y acertadamente, FERNÁNDEZ Y OLAVARRÍA (2018), pp.1253 y ss.

${ }^{88}$ En detalle al respecto, MAÑALICH (2010a), pp. 208 y ss.

${ }^{89}$ Se trata de una suspensión, y no de una interrupción de la prescripción, no obstante, el uso que en esa misma disposición se hace del participio "interrumpido", por el hecho de que la propia disposición reconoce que, en tal caso, ha de considerarse que el plazo ha transcurrido como si no hubiese tenido lugar la prosecución, que es lo propio, justamente, de una suspensión.
} 
ejercer el Ministerio Público dependerá de que el plazo de prescripción haya ya transcurrido íntegramente ${ }^{90}$, computado a partir del instante de la terminación del eventual hecho punible al cual pudiera encontrarse referido el nuevo juzgamiento ${ }^{91}$. La brevedad de los plazos de prescripción previstos en el art. 94 del CP, y en general en la legislación penal chilena, vuelve altamente probable que el beneficiado por la respectiva sentencia de revisión haya de quedar inmunizado, a través de la excepción de prescripción, frente a la eventualidad de una nueva persecución.

\section{BIBLIOGRAFÍA CITADA}

ACCATINO, DANIELA (2011): “Certezas, dudas y propuestas en torno al estándar de la prueba penal”, en: Revista de Derecho de la Pontificia Universidad Católica de Valparaíso (Vol. XXXVII), pp. 483-511.

ALONSO, JUAN PABLO (2018): “Principios implícitos y fuentes sociales del derecho”, en: DOXA (Vol. 41), pp. 63-83.

ATRIA, FERnANDO (2016): La forma del derecho (Madrid, Barcelona, Buenos Aires y San Pablo, Marcial Pons).

BAYÓN, JUAN CARLOS (2000): “Derechos, democracia y constitución", en: Discusiones (Vol. I), pp. 65-94.

(2009): "Epistemología, moral y prueba de los hechos: hacia un enfoque no benthamiano", en: Analisi e Diritto (2008), pp. 15-34.

BENNECKE, HANS Y BELING, ERNST (1900): Lehrbuch des Deutschen Reichs-Strafprozessrechts (Breslau, Schletter'sche Buchhandlung).

BINDING, KARL (1915): Strafrechtliche und strafprozessuale Abhandlungen (Múnich y Léipzig, Duncker \& Humblot), tomo II.

CARBONELL, FLAVIA (2017): "Elementos para un modelo de decisión judicial correcta", en: Revista de Estudios de la Justicia (№ 27), pp. 1-35.

CARNELUTTI, FRANCESCO (1961): Cuestiones sobre el proceso penal (Traducc. Santiago Santís Melendo, Buenos Aires, Ediciones Jurídicas Europa-América).

CASTILLO, IGNACIO (2013): "Enjuiciando al proceso penal chileno desde el inocentrismo (algunos apuntes sobre la necesidad de tomarse en serio a los inocentes)", en: Política Criminal (Vol. 8, № 13), pp. 249-313.

CELANO, BRUNO (2001): “Justicia procedimental pura y teoría del derecho", en: DOXA (№ 24), pp. 407427.

\footnotetext{
${ }^{90}$ Véase ya BINDING (1915), p. 296.

${ }^{91}$ Al respecto MAÑALICH (2010a), pp. 162 ss. y 209.
} 
COLOMA, RODRIGO (2017): "Bases de un modelo conceptual para decidir hechos", en: DOXA (№ 40), pp. 69-92.

DEI VECCHI, DIEGO (2014): “Acerca de la fuerza de los enunciados probatorios: el salto constitutivo", en: DOXA (№ 37), pp. 237-261.

DEL Río, CARLOS (2009): Los poderes de decisión del juez penal (Santiago, Editorial Jurídica de Chile).

DUCE, MAURICIO (2015): "La condena de inocentes en Chile: una aproximación empírica a partir de los resultados de los recursos de revisión acogidos por la Corte Suprema en el periodo 2007-2013", en: Política Criminal (Vol. 10, № 19), pp. 159-191.

(2017): "Los recursos de revisión y la condena de inocentes en Chile: una aproximación empírica en el periodo 2007-2016", en: Doctrina y Jurisprudencia Penal (№ 30), pp. 3-40.

DUCE, MAURICIO Y RIEGO, CRISTIÁN (2007): Proceso penal (Santiago, Editorial Jurídica de Chile).

DUFF, ANTONY (1986): Trials and Punishments (Cambridge, Cambridge University Press).

FERNÁNDEZ, JOSÉ MANUEL Y OLAVARRÍA, MALVA (2009): "Teoría y práctica de la acción de revisión en el nuevo Código Procesal Penal, causal letra d) del artículo 473", en: lus et Praxis (Vol. 15, № 2), pp. 215-255.

FERNÁNDEZ, JOSÉ MANUEL Y OLAVARRÍA, MALVA (2018): “Examinando de nuevo la acción de revisión”, en: Política Criminal (Vol. 13, № 26), pp. 1190-1285.

FERRER, JORDI (2005): Prueba y verdad en el derecho, 2ª ed. (Madrid, Barcelona y Buenos Aires, Marcial Pons).

(2007): La valoración racional de la prueba (Madrid, Barcelona y Buenos Aires, Marcial

Pons).

(2012A): "El error judicial y los desacuerdos irrecusables en el derecho", en: Luque, Pau y Ratti, Giovanni (eds.), Acordes y desacuerdos. Cómo y por qué los juristas discrepan (Madrid, Barcelona, Buenos Aires y San Pablo, Marcial Pons), pp. 259-274.

(2012B): “Una concepción minimalista y garantista de la presunción de inocencia”, en: Moreso, José Juan y Martí, José Luis (eds.), Contribuciones a la filosofía del derecho. Imperia en Barcelona 2010 (Madrid, Barcelona, Buenos Aires y San Pablo, Marcial Pons), pp. 167-186.

FINDLEY, KEITH (2010): “Defining innocence”, en: Albany Law Review (№ 74), pp. 1157-1208.

FRISTER, HELMUT (2016): "Die Unschuldsvermutung", en: Herzog, Felix et al. (coords.), Rechtsstaatlicher Strafprozess und Bürgerrechte. Gedächtnisschrift für Edda Weßlau (Berlín, Duncker \& Humblot), pp. 149-163. 
GARRIDO, MARIO (2010): Derecho Penal. Parte Especial, 4a ed. (Santiago, Editorial Jurídica de Chile), tomo III.

GONZÁLEZ LAGIER, DANIEL (2011): “Argumentación y prueba judicial”, en: Ferrer, Jordi et al., Estudios sobre la prueba (Ciudad de México, Fontamara, segunda edición), pp. 103-148.

GRECO, LUIS (2015): Strafprozesstheorie und materielle Rechtskraft (Berlín, Duncker \& Humblot).

HACKER, P.M.S. (2013): The Intellectual Powers. A Study of Human Nature (Malden [Mass.], Oxford y Chichester [West Sussex], Wiley-Blackwell).

HORVITZ, MARÍA INÉS Y LÓPEZ, JULIÁN (2004): Derecho Procesal Penal Chileno (Santiago, Editorial Jurídica de Chile), tomo II.

HÖRNLE, TATJANA (2004): "Justice as Fairness - Ein Modell auch für das Strafverfahren?", en: Rechtstheorie (№ 35), pp. 175-194.

KINDHÄUSER, URS (1984): “Rohe Tatsachen und normative Tatbestandsmerkmale”, en: Jura (1984), pp. 465-478.

KOTSOGLOU, KYRIAKOS (2014): "Über die Bedeutungslosigkeit des Satzes, in dubio pro reo', en: Zeitschrift für Internationale Strafrechtsdogmatik 1/2014. Disponible en: http://www.zisonline.com/dat/artikel/2014_1_791.pdf [visitado el 11 de mayo de 2019].

LARROUCAU, JORGE (2012): "Hacia un estándar de prueba civil", en: Revista Chilena de Derecho (Vol. 39, № 3), pp. 783-802.

LASCURAÍN, ANTONIO Y GASCÓN, FERNANDO (2018): “¿Por qué se conforman los inocentes?”, en: InDret 3/2018. Disponible en: http://www.indret.com/pdf/1400.pdf [visitado el 11 de mayo de 2019].

LAUDAN, LARRY (2006): Truth, Error, and Criminal Law (Cambridge, Cambridge University Press).

LETELIER, RAÚl (2018): “El precio del statu quo. Sobre el estándar probatorio en las sanciones administrativas", en: Revista de Derecho, UACh (Vol. XXXI, № 1), pp. 209-229.

MAÑALICH, JUAN PABLO (2008): "Miedo insuperable y obediencia jerárquica", en: Revista de Derecho, UACh (Vol. XXI, № 1), pp. 61-73.

(2010A): Terror, pena y amnistía (Santiago, Flandes Indiano).

(2010B): "La estructura de la autoría mediata", en: Revista de Derecho de la Pontificia Universidad Católica de Valparaíso (Vol. XXXIV), pp. 385-414. 
(2014A): "Merecimiento, distribución y teodicea. El derecho penal en la teoría rawlsiana de la justicia", en: Grez, Pablo et al. (coords.), Una vida en la Universidad de Chile: celebrando al Profesor Antonio Bascuñán Valdés (Santiago, Legal Publishing/Thomson Reuters), pp. 389-415.

(2014B): Norma, causalidad y acción (Madrid, Barcelona, Buenos Aires y San Pablo, Marcial Pons).

(2017): "La tentativa de delito como hecho punible", en: Revista Chilena de Derecho (Vol. 44, № 2), pp. 461-493.

(2018): Estudios sobre la fundamentación y la determinación de la pena (Santiago, Thomson Reuters).

MOSQUERA, MARIO Y MATURANA, CRISTIÁN (2012): Los recursos procesales, 2aa ed. (Santiago, Editorial Jurídica de Chile).

NAVARRO, PABLO Y RODRÍGUEZ, JORGE LUIS (2014): Deontic Logic and Legal Systems (Nueva York, Cambridge University Press).

NEUMANN, ULFRID (1989): "Materiale und prozedurale Gerechtigkeit im Strafverfahren", en: Zeitschrift für die gesamte Strafrechtswissenschaft (Vol. 101), pp. 52-74.

OLIVER, GUILLERMO (2007): Retroactividad e irretroactividad de las leyes penales (Santiago, Editorial Jurídica de Chile).

PAILLAS, ENRIQUE (2001): La revisión en materia penal (Santiago, LexisNexis).

PUTNAM, HILARY (2002): The Collapse of the Fact/Value Dichotomy (Cambridge [Mass.] y Londres, Harvard University Press).

RADBRUCH, GUSTAV (1967): Der Handlungsbegriff in seiner Bedeutung für das Strafrechtssystem, ed. de Arthur Kaufmann (Darmstadt, Wissenschaftliche Buchsgesellschaft).

RAWLS, JOHN (1999): A Theory of Justice, 2a ed. (Cambridge [Mass.], The Belknap Press).

SEHER, GERHARD (2006): "Kann Strafrecht ,subsidiär' sein? Aporien eines ,unbestrittenen" Rechtsgrundsatzes", en: Von Hirsch, Andrew et al. (eds.), Mediating Principles. Begrenzungsprinzipien bei der Strafbegründung (Baden-Baden, Nomos), pp. 70-82.

STUCKENBERG, CARL-FRIEDRICH (1998): Untersuchungen zur Unschuldsvermutung (Berlín y Nueva York, Walter de Gruyter).

VALENZUELA, JONATAN (2017): Hechos, pena y proceso (Santiago, Rubicón). 
VERNENGO, NANCY (2015): La revisión de la sentencia firme en el proceso penal, tesis doctoral presentada en la Universidad de Barcelona. Disponible en: https://www.tesisenred.net/handle/10803/298301 [visitada el 09 de mayo de 2019].

WILENMANN, JAVIER (2014): "Sobre la estructura dogmática de los delitos de falsedad en el proceso", en: lus et Praxis (Vol. 20, № 2), pp. 71-108.

\section{JURISPRUDENCIA CITADA}

RODRIGO EDUARDO SAAVEDRA CONUS (2011): Corte Suprema 28 de julio (acción de revisión), Rol № 28272011.

TRIBUNAL CONSTITUCIONAL FEDERAL ALEMÁN (BVERFG), decisión del 14.09.2006 - 2 BvR 123/06, 2 BvR 429/06, 2 BvR 430/06.

\section{NORMAS JURÍDICAS CITADAS}

CONSTITUCIÓN POLÍTICA DE LA REPÚBLICA. Diario Oficial, 24 de octubre de 1980.

CÓDIGO DE PROCEDIMIENTO PENAL. Diario Oficial, 13 de febrero de 1906.

CÓDIGO DE PROCEDIMIENTO CIVIL. Diario Oficial, 30 de octubre de 1902.

CÓDIGO PROCESAL PENAL. Diario Oficial, 12 de octubre de 2000.

CÓDIGO ORGÁNICO DE TRIBUNALES. Diario Oficial, 9 de julio de 1943.

CóDIGO PENAL. Diario Oficial, 12 de noviembre de 1874.

LEY № 19.640, ORGÁNICA CONSTITUCIONAL DEL MINISTERIO PÚBLICO. Diario Oficial, 15 de octubre de 1999.

LEY DE ENJUICIAMIENTO CRIMINAL, ESPAÑA. BOE № 260, 17 de septiembre de 1882

Ordenanza Procesal Penal: Alemania. 1ㅇ de febrero de 1877. 